Universidade de Brasília - UnB

Faculdade de Economia, Administração, Contabilidade

e Ciência da Informação - FACE

11 2 Programa de Pós-Graduação em Administração - PPGA

ALCIONE SARAH SANTOS COSTA

AVALIAÇÃO DA QUALIDADE DE SERVIÇOS EM UM SETOR DE ATENDIMENTO EM UMA INSTITUIÇÃO DE ENSINO SUPERIOR 


\title{
AVALIAÇÃO DA QUALIDADE DE SERVIÇOS EM UM SETOR DE ATENDIMENTO EM UMA INSTITUIÇÃO FEDERAL DE ENSINO SUPERIOR
}

\author{
Monografia apresentada ao curso de Gestão \\ Universitária da Faculdade de Economia, \\ Administração, Contabilidade e Ciência da Informação \\ e Documentação - FACE, da Universidade de Brasília \\ como requisito parcial à obtenção do grau de \\ especialista em Gestão Universitária.
}

Orientadora: Prof ${ }^{a}$ Josivania Silva Farias

\author{
Brasília - DF
}


Universidade de Brasília - UnB

Faculdade de Economia, Administração, Contabilidade e Ciência da Informação - FACE

Programa de Pós-Graduação em Administração - PPGA

\section{AVALIAÇÃO DA QUALIDADE DE SERVIÇOS EM UM SETOR DE ATENDIMENTO DE UMA INSTITUIÇÃO FEDERAL DE ENSINO SUPERIOR}

Banca Examinadora

Dra Catarina Cecília Odelius

Examinadora

Prof ${ }^{\text {a }}$ MSc. Josivania Silva Farias

Orientadora

Brasília, 07 de maio de 2009. 
Dedico este estudo a Deus, autor da minha vida e da minha história e à minha família, minha maior riqueza. 


\section{AGRADECIMENTOS}

À Deus, pelo dom da vida.

À minha família por todo o apoio recebido nas horas mais difíceis e pela confiança em mim depositada.

Aos professores do Curso de Especialização em Gestão Universitária pela competência com que compartilharam seus conhecimentos.

À prof ${ }^{a}$ Josivania Silva Farias pela orientação competente e dedicada.

À Universidade de Brasília por oferecer um curso tão rico em conhecimentos.

À minha tia Lindalva por me proporcionar infinitas oportunidades de crescimento pessoal e profissional.

Ao meu pai Adalberto e meu irmão Júnior por tudo que fazem por mim apesar da distância.

Ao meu irmão Adamylson pela ajuda e apoio incondicional.

A Matteo, pela força e palavras de encorajamento que me impediram de desistir dessa caminhada.

Aos colegas de Curso, em especial a Aluísio Xavier, Danielle Coelho e Eleusa Leal (minha irmãzinha), pelo companheirismo e apoio nos momentos difíceis.

Aos alunos de graduação da Universidade de Brasília pela disposição e colaboração na coleta de dados para o desenvolvimento deste trabalho.

Enfim, a todos os meus amigos e amigas que não foram aqui citados (as) nominalmente, mas que tenho certeza que estão sempre me incentivando e torcendo por mim. 
"Dá-se muita atenção ao custo de se realizar algo. E nenhuma ao custo de não realizá-lo."

(Philip Kotler) 


\section{RESUMO}

Esta pesquisa teve como objetivo avaliar a qualidade dos serviços oferecidos pela Secretaria de Assuntos Acadêmicos (SAA) da Universidade de Brasília. Inicialmente foi realizada uma revisão bibliográfica, cujo referencial teórico abordou temas sobre marketing, marketing dos serviços, serviços, atendimento ao publico, satisfação e qualidade dos serviços. A pesquisa foi feita junto a 200 alunos de graduação da Universidade de Brasília. Para a coleta de dados sobre a expectativa e a percepção dos usuários quanto à qualidade dos serviços prestados pela SAA foi adotada e escala SERVQUAL criada e validada por Parasuraman, Berry e Zeithalm (1985), além de terem sido incluídas algumas questões ao final da Escala para verificar dados que permitissem traçar o perfil dos usuários participantes da pesquisa (sexo, idade, estado civil, vínculo empregatício, tempo de universidade, renda mensal familiar e área de estudo). Foi feita análise descritiva dos dados e os resultados apresentados apontaram Gaps preocupantes, pois indicam que os alunos-usuários da SAA estão insatisfeitos com a qualidade dos serviços oferecidos. No entanto, sugere-se a realização de estudos mais aprofundados para esclarecer alguns resultados obtidos com esse estudo.

Palavras-chave: satisfação, serviços, qualidade, SERVQUAL. 


\section{LISTA DE FIGURAS}

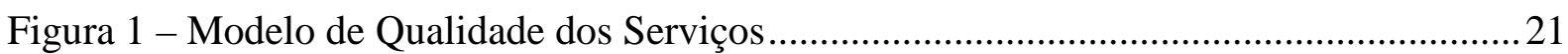

Figura 2 - Fórmula para o cálculo dos Gaps de Qualidade dos Serviços ................................29

\section{LISTA DE TABELAS}

Tabela 1 - Escore das escalas de opinião utilizada no instrumento SERVQUAL ..................28

Tabela 2 - Distribuição das respostas de acordo com a frequência................................................. 34

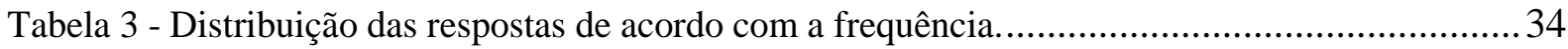

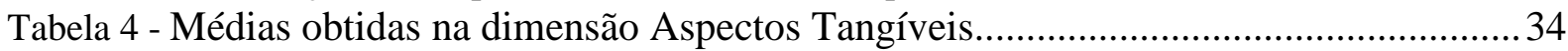

Tabela 5 - Distribuição das respostas de acordo com a frequência...........................................35

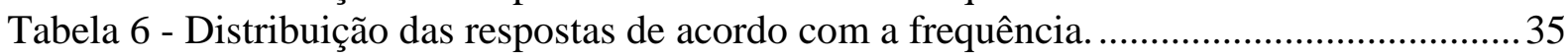

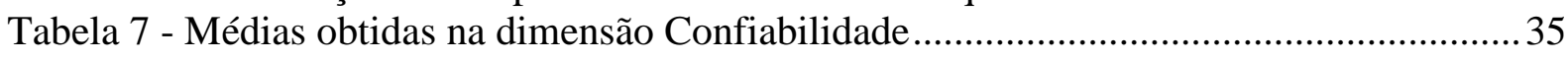

Tabela 8 - Distribuição das respostas de acordo com a frequência......................................... 36

Tabela 9 - Distribuição das respostas de acordo com a frequência.......................................... 36

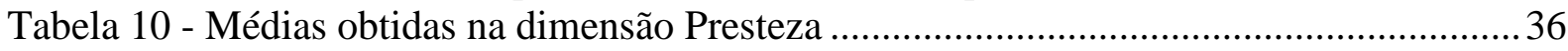

Tabela 11 - Distribuição das respostas de acordo com a frequência........................................37

Tabela 12 - Distribuição das respostas de acordo com a frequência........................................37

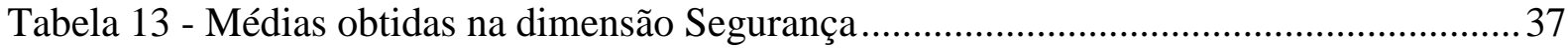

Tabela 14 - Distribuição das respostas de acordo com a frequência....................................... 38

Tabela 15 - Distribuição das respostas de acordo com a frequência....................................... 38

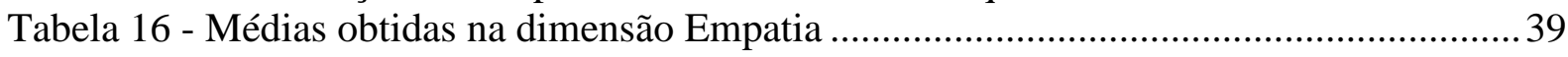

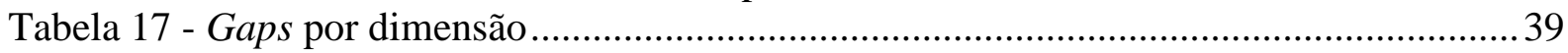

\section{LISTA DE QUADROS}

Quadro 1 - Determinantes da qualidade (PARASURAMAN e al., 1985). 


\section{SUMÁRIO}

1. INTRODUÇÃ

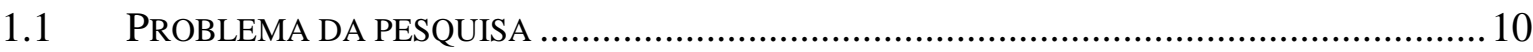

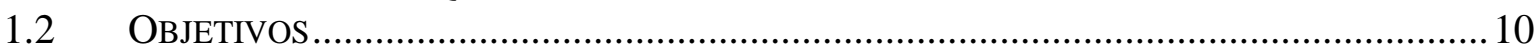

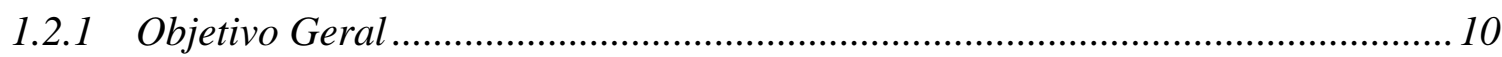

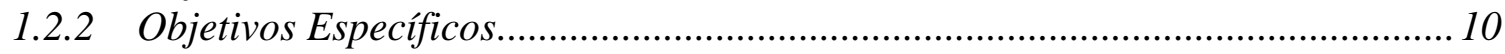

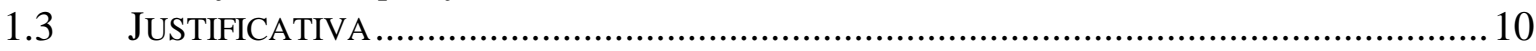

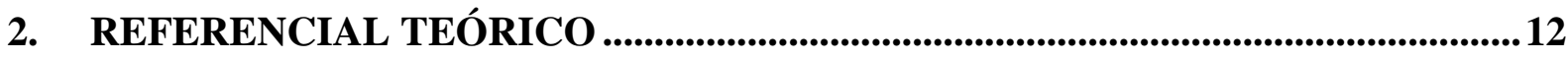

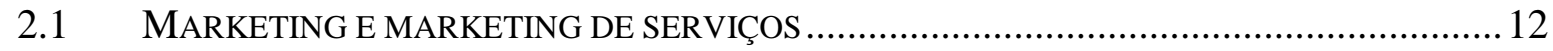

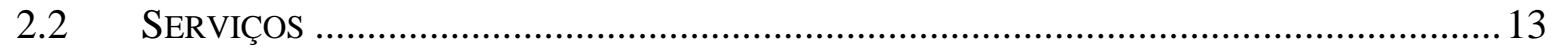

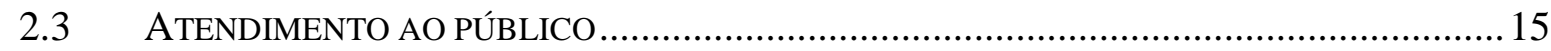

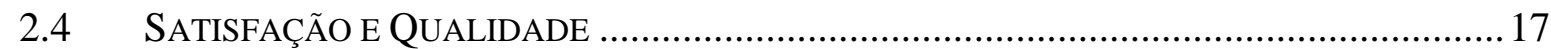

2.5 A PREOCUPAÇÃO COM A QUALIDADE NO SERVIÇO PÚBLICO …................................23

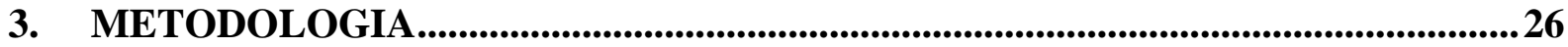

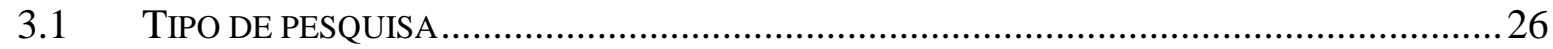

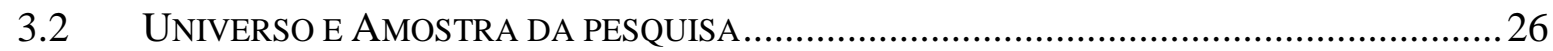

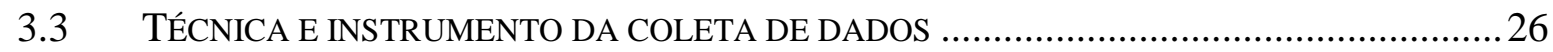

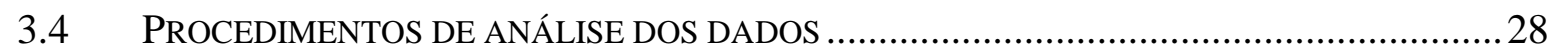

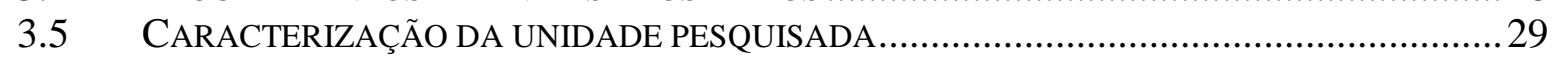

4. APRESENTAÇÃO E DISCUSSÃO DOS RESULTADOS .......................................... 32

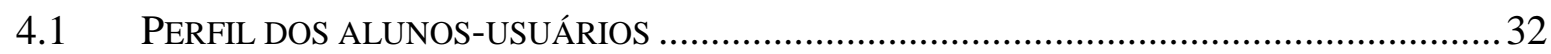

4.2 AVALIAÇÃO DAS EXPECTATIVAS E PERCEPÇÕES DO ALUNO-USUÁRIO QUANTO

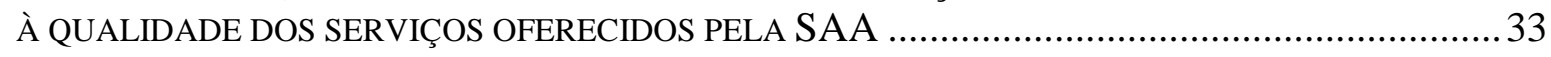

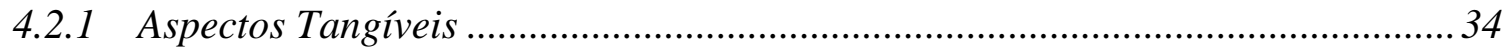

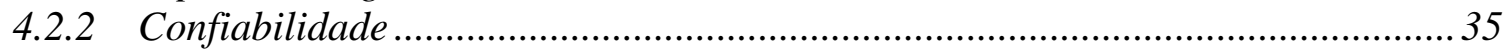

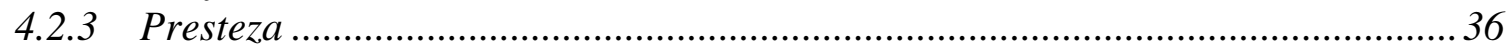

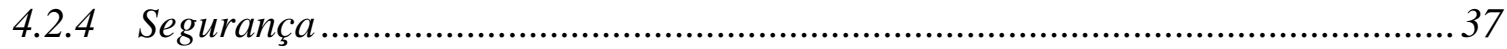

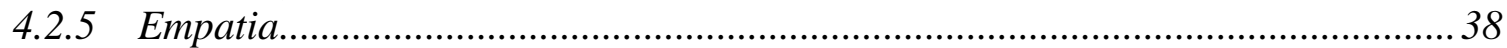

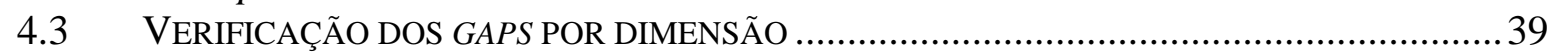

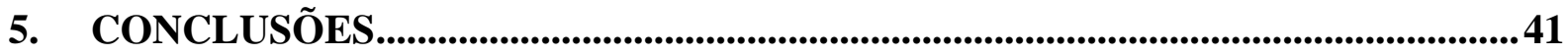

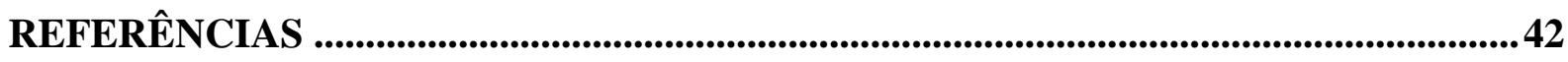

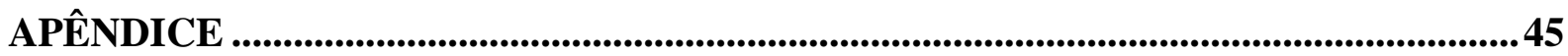




\section{INTRODUÇÃO}

O setor de serviços, na segunda metade do século $X X$, cresceu em participação e importância em todos os países industrializados. Paralelamente, aumentou-se, a cada dia, a atenção dada à qualidade dos serviços e à satisfação dos clientes, o que tem mobilizado a ação de muitos gerentes de organizações voltadas para os serviços. Muito foi feito para melhorar a qualidade e a satisfação dos clientes durante os anos 80 e 90, entretanto, serviços considerados medíocres ainda são um fato observado em todo o mundo (HAKSEVER, 2000 apud AMARAL; PINTO; MIRANDA, 2002).

Segundo Lovelock (1983 apud MELLO et al., 2002), o serviço educacional é classificado como um serviço de ações intangíveis, dirigido à mente das pessoas, de entrega contínua, realizado através de uma parceria entre a organização de serviço e seu cliente, com um alto contato pessoal é baixa customização.

Conforme Marcelino (2003), as universidades federais brasileiras, como toda a administração pública nacional, passam por intensas transformações, resultado de avanços tecnológicos e de relevantes mudanças de ordem social, econômica e política. O modelo burocrático, que evoluiu a partir de 1930, não atende ao novo momento da sociedade brasileira.

A qualidade do serviço de atendimento ao público no contexto da realidade brasileira, tanto no âmbito estatal quanto na iniciativa privada, apresenta-se como um desafio institucional que necessita de transformações urgentes. Essa necessidade tem múltiplas facetas, e a visibilidade de uma delas se expressa nas queixas freqüentes de usuáriosconsumidores (FERREIRA, 2000).

Assim, faz-se necessário examinar novas referências para o planejamento e para a organização das unidades acadêmicas na busca de atender demandas, como: prestação de serviços com qualidade, usando novas tecnologias, para obter eficiência interna e eficácia organizacional (MARCELINO, 2003). 


\subsection{Problema da pesquisa}

Percebe-se por meio de diversas pesquisas que o cliente/consumidor é um ator cada vez mais exigente e informado. A mensuração da qualidade dos serviços tem sido tema recorrente de estudos, por ser de notória importância aumentar o grau de satisfação do cliente em relação ao atendimento recebido, principalmente em instituições privadas, que têm como objetivo o lucro, sejam elas de bens ou de serviços.

Uma instituição pública de ensino superior, embora não vise lucro, deve despertar para uma melhoria no aumento da eficácia, da eficiência e da qualidade quanto à prestação de serviços.

Cada cliente/consumidor, no caso desse estudo, o aluno, é único no que se refere tanto aos comportamentos quanto às atitudes. Avaliar a sua satisfação diante do serviço recebido é de suma importância.

Diante do exposto chega-se a seguinte questão: a Secretaria de Assuntos Acadêmicos (SAA) da Universidade de Brasília oferece um serviço de qualidade percebido pelos alunos da graduação?

\subsection{Objetivos}

\subsubsection{Objetivo Geral}

Identificar o nível de qualidade dos serviços da Secretaria de Assuntos Acadêmicos (SAA) da Universidade de Brasília, sob a ótica dos alunos-usuários.

\subsubsection{Objetivos Específicos}

- Identificar o grau de expectativa do usuário em relação aos serviços recebidos.

- Identificar o grau de satisfação do usuário em relação aos serviços recebidos.

- Conhecer a lacuna (gap) entre a expectativa e o desempenho da Instituição com relação aos serviços prestados.

\subsection{Justificativa}

Os avanços do capitalismo mundial na última década lançaram as empresas em uma disputa por qualidade em âmbito mundial, criando um contexto onde a satisfação do consumidor tornou-se de suma importância (BEBER, 1999). 
A qualidade nos serviços já é um grande desafio, pois vivemos em um mundo globalizado, onde a concorrência mercadológica se apresenta cada vez mais acirrada. A satisfação e insatisfação têm sido temas freqüentes em pelo menos 15.000 artigos práticos e acadêmicos (PETERSON; WILSON, 1992 apud CUNHA et al., 1998).

Mensurar a qualidade em serviços não é uma tarefa fácil, porém necessária diante de clientes cada vez mais exigentes e conscientes de seus direitos como consumidores.

Uma instituição de ensino como a Universidade de Brasília, importante fornecedora de serviços, é por si um locus interessante para esse tipo de pesquisa, principalmente agora que está diante da implantação do novo Programa de Gestão e Avaliação do Desempenho (PROGED). Este foi instituído por meio da Resolução do Conselho de Administração no 9/2008 da Fundação Universidade de Brasília (FUB) como um dos fatores que integram a Carreira dos Cargos Técnico-Administrativos em Educação da FUB, estabelecendo critérios e apresentando, entre outros itens, a avaliação do atendimento sob a ótica dos usuários.

Este é um estudo viável, no que se refere ao tempo de realização e às referências disponíveis, além de não depender de financiamentos de agências de fomento. 


\section{REFERENCIAL TEÓRICO}

Este capítulo apresenta os conceitos básicos nos quais a pesquisa está centrada: marketing e marketing de serviços, serviços, atendimento ao público, satisfação e qualidade.

Para isso, recorreu-se a vários autores, como Lovelock e Wright (2003), Kotler e Keller (2006).

\subsection{Marketing e marketing de serviços}

Conforme Limeira (2003, p. 34):

marketing é uma palavra em inglês derivada de market, que significa mercado; seu conceito surgiu no pós-guerra, na década de 1950, quando a industrialização em todo o mundo avançou aumentando a concorrência e a disputa de mercado entre as empresas.

Las Casas (1991) definiu marketing como:

área do conhecimento que engloba todas as atividades concernentes à relação de troca, orientadas para a satisfação dos desejos e necessidades dos consumidores, visando alcançar determinados objetivos da organização ou indivíduo considerando sempre o meio ambiente de atuação e o impacto que estas relações causam no bemestar da sociedade.

De acordo com a American Marketing Association (AMA) ${ }^{1}$ (Kotler e Keller, 2006, p. 4), “marketing é o processo de planejar e executar a concepção, a determinação do preço (pricing), a promoção e distribuição de idéias, bens e serviços para criar trocas que satisfaçam metas individuais e organizacionais".

Para Kotler e Keller (2006, p. 5), “a troca é o conceito central do marketing, pois envolve a obtenção de um produto desejado de alguém, oferecendo algo em troca".

Para que o potencial da troca possa existir, são necessárias cinco condições:

1. que existam duas partes;

2. que todas as partes possuam algo que possa ter valor para as outras partes;

3. que todas as partes tenham capacidade de comunicação e entrega;

4. que todas as partes estejam livres para aceitar ou recusar oferta de troca;

5. que todas as partes acreditem ser adequado.

\footnotetext{
1 É um misto de associação acadêmica e profissional, voltada tanto para questões de treinamento e desenvolvimento empresarial, quanto para o desenvolvimento do conhecimento na área de marketing. Trata-se de uma organização conceituada, composta por aproximadamente 40 mil membros e existe há mais de sessenta anos. Muitos profissionais a vêem como o órgão que estabelece as práticas e a educação relacionadas a marketing.
} 
Para Cobra (1990, p.35), o próprio papel do marketing consiste em:

Identificar necessidades não satisfeitas, de forma a colocar no mercado produtos ou serviços que, ao mesmo tempo, proporcionem satisfação dos consumidores, gerem resultados auspiciosos aos acionistas e ajudem a melhorar a qualidade de vida das pessoas e da comunidade em geral.

\subsection{Serviços}

Para Kotler e Keller (2006, p.397), serviço é qualquer ato ou desempenho, essencialmente intangível, que uma parte pode oferecer à outra e que não resulta na propriedade de nada, e sua execução pode estar ou não ligada a um produto concreto.

Segundo Lovelock e Wright (2003, p. 5), há duas definições que capturam a essência dos serviços:

1. Serviço é um ato ou desempenho oferecido por uma parte à outra. Embora o processo possa estar ligado a um produto físico, o desempenho é essencialmente intangível e normalmente não resulta em propriedade de nenhum dos fatores de produção.

2. Serviços são atividades econômicas que criam valor e fornecem benefícios para clientes em tempos e lugares específicos, como decorrência da realização de uma mudança desejada no - ou em nome do - destinatário de serviço.

Ainda Lovelock e Wright (2003, p. 32) classificam os serviços de forma significativa, como exposto a seguir:

$\checkmark$ Grau de tangibilidade ou intangibilidade de processos de serviços: processos de serviços diferentes não apenas moldam a natureza do sistema de entrega do serviço, mas, também afetam o papel dos funcionários e a experiência dos clientes.

$\checkmark$ Destinatário direto do processo de serviço: a natureza do encontro de serviço entre fornecedores e clientes varia amplamente de acordo com a medida na qual os próprios clientes são integralmente envolvidos no processo de serviços.

$\checkmark$ Tempo e lugar de entrega do serviço: o serviço deve ir até o cliente ou vice-versa?

$\checkmark$ Personalização versus padronização: todos os clientes devem receber o mesmo serviço ou às características dos serviços devem ser adaptados para satisfazer necessidades individuais?

$\checkmark$ Natureza da relação com os clientes: alguns serviços envolvem uma relação formal na qual cada cliente é conhecido pela organização e todas as transações são registradas e cadastradas individualmente, mas, em outros serviços clientes não identificados empreendem transações passageiras e depois desaparecem da organização.

$\checkmark$ Medida na qual a oferta e a demanda estão em equilíbrio: a capacidade deve ser ajustada para acomodar o nível de demanda ou devem-se implementar estratégias de marketing para predizer, administrar e uniformizar os níveis de demanda para equilibrá-los com a capacidade. 
$\checkmark$ Medida na qual instalações, equipamentos e pessoal participam da experiência de serviços: as experiências dos clientes com os serviços são moldadas, em parte pela medida na qual eles são expostos a elementos tangíveis no sistema de entrega do serviço.

Os serviços segundo Lovelock e Wright (2003) possuem as seguintes características:

- Intangibilidade: os serviços não podem ser vistos, sentidos, ouvidos, cheirados ou provados antes de adquiridos.

- Inseparabilidade: os serviços são produzidos e consumidos simultaneamente.

- Variabilidade: os serviços são altamente variáveis, pois dependem de por quem, onde e quando são fornecidos.

- Perecibilidade: os serviços não podem ser estocados.

Os serviços intangíveis "são produzidos e consumidos simultaneamente. Isso não é verdadeiro para bens físicos que são fabricados, estocados, distribuídos através de revendedores múltiplos e, posteriormente, consumidos" (KOTLER, 1998).

Para Parasuraman et al. (1988 apud FREITAS, 2008) existem três características essências para os serviços:

- Simultaneidade: serviços são consumidos quase que simultaneamente ao momento em que são produzidos, tornando difícil ou quase impossível detectar e corrigir as falhas antes que elas ocorram e afetem o cliente.

- Intangibilidade: os serviços representam um produto não físico, ou seja, não podendo ser transportados ou armazenados.

- Heterogeneidade: a grande variedade de serviços existentes e o forte relacionamento com o fator humano dificultam a atividade de padronização e estimação de preços.

Grönroos (1995) define serviço como:

uma atividade ou série de atividades de natureza mais ou menos intangível - que normalmente, mas não necessariamente, acontece durante as interações entre clientes e empregados de serviço e/ou recursos físicos ou bens e/ou sistemas do fornecedor de serviços - que é fornecida como solução ao(s) problema(s) do(s) cliente(s).

Giacomini (1995, apud Mello, 2001) defendeu a ampliação do conceito de serviços, aplicando-o adequadamente ao serviço educacional; isto porque embora, a instituição ofereça itens básicos - aulas, bibliotecas, avaliações e outros - é necessário que outros serviços e produtos existam para que se efetue o consumo plenamente. Não são raras as 
oportunidades em que a falta de um serviço complementar inviabilize o oferecimento do item básico não havendo para isso uma hierarquia lógica de importância do que é oferecido.

Deve-se considerar o fato de que o serviço oferecido deve proporcionar alta satisfação ao consumidor, além de vantagem competitiva para a empresa por que:

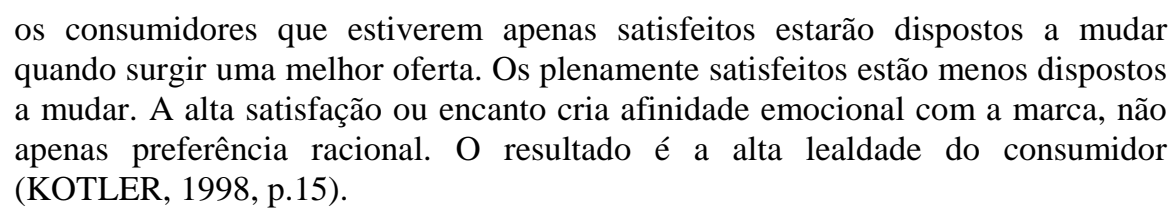
quando surgir uma melhor oferta. Os plenamente satisfeitos estão menos dispostos a mudar. A alta satisfação ou encanto cria afinidade emocional com a marca, não apenas preferência racional. O resultado é a alta lealdade do consumidor (KOTLER, 1998, p.15).

Devido à grande variedade de serviços oferecidos, segundo Kotler e Keller (2006, p.398), fica difícil generalizá-los sem uma distinção profunda:

- Os serviços podem ser baseados em equipamentos ou em pessoas.

- As organizações prestadoras de serviços podem optar por diferentes processos para oferecer serviços.

- Alguns serviços exigem a presença do cliente outros não.

- Os serviços diferem quanto ao tipo de atendimentos que atendam necessidades pessoais ou de empresas.

- Prestadores de serviços diferem em objetivos (com ou sem fins lucrativos) e em propriedade (privados ou públicos).

De acordo com a Norma NBR 9004-2 (1994), serviço é definido como resultado gerado por atividades de interação entre fornecedor e cliente, bem como atividades internas da organização, para satisfazer as necessidades do cliente.

\subsection{Atendimento ao público}

Para Ferreira (2000, p. 4) o atendimento ao público é um serviço complexo. Tratase de uma atividade social mediadora, que coloca em cena a interação de diferentes sujeitos em um contexto específico, visando a responder a distintas necessidades, e complementa:

A instituição enquanto palco onde se desenrola o atendimento como atividade social, não é neutra; ao contrário, os objetivos, os processos organizacionais e a estrutura existente são elementos essenciais conformadores da situação de atendimento. Eles têm a função de contexto institucional facilitador e/ou dificultador da interação entre os sujeitos, da qualidade do serviço, e imprimem uma dinâmica singular no cenário onde se efetua o atendimento. (FERREIRA, 2000, p. 4). 
Diagnosticar o serviço de atendimento ao público, segundo Ferreira (2000, p. 5), para identificar a origem e a dinâmica dos problemas existentes e, ainda, aprimorar a sua qualidade, impõem compreender:

- a lógica da instituição: identificar e analisar o conjunto de fatores (perfil, processos organizacionais e recursos instrumentais), que caracteriza o "modo de ser habitual" da instituição, sem o qual é impossível compreender o que se passa nas situações de atendimento e os efeitos sobre sua eficácia e qualidade;

- a lógica do (a) atendente: identificar e analisar o conjunto de fatores (perfil individual, competência profissional e estado de saúde), que caracteriza o "modo operatório usual" do atendente, orientando a sua conduta nas situações de atendimento para responder adequadamente tanto às necessidades dos usuários quanto às tarefas prescritas pela instituição; $\mathrm{e}$

- a lógica do usuário: identificar e analisar o conjunto de fatores (perfil socioeconômico, representação social e satisfação), que caracteriza o "modo de utilização" dos serviços pelos usuários e que orienta seus comportamentos nas situações de atendimento ao público.

O atendimento ao público no setor privado se diferencia do setor público, tanto no que se refere aos objetivos estabelecidos, quanto pelos problemas inerentes à especificidade de cada um. Nessa perspectiva, Epstein (1991 apud HOSTENSKY, p.20) distingue cinco categoriais de limites constatados no atendimento ao público nos órgãos governamentais, que diferenciam de forma significativa, as condutas dos usuários:

$\checkmark$ informação: os consumidores não possuem informações sobre os serviços disponíveis e esse fato se relaciona com os jargões administrativos utilizados na divulgação das informações;

$\checkmark$ acesso: a dificuldade de acesso aos serviços públicos pode ser dividida em física (distância, horários, local, sinalização), social (barreiras sociais, impessoalidade, negligência) e institucional (complexidade dos processos decisórios e das regras);

$\checkmark$ opção: muitas vezes os consumidores dos serviços públicos não encontram outras opções de serviços que atendam melhor suas expectativas;

$\checkmark$ reparação: relaciona-se ao reparo (ou a possibilidade de obter desculpas) quando os órgãos públicos cometem erros;

$\checkmark$ representação: refere-se à impossibilidade de os consumidores influenciarem o processo decisório, sendo considerada pouco relevante para o sistema.

Segundo Dantas (2004), são seis os componentes do atendimento:

$\checkmark$ Clientes - são todas as pessoas físicas ou jurídicas que utilizam regularmente os serviços da organização.

$\checkmark$ Atendentes - são todos os funcionários de uma organização que têm contato direto com o público.

$\checkmark$ Normas e regulamentos - são as leis, decretos, regulamentos, normas internas, etc., que norteiam a organização e a forma de oferta de prestação de serviços. 


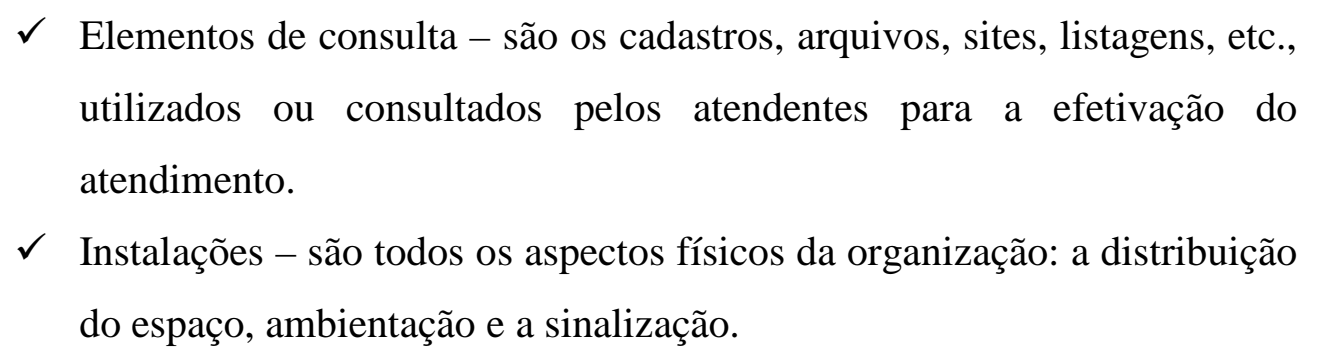

Ferreira (2000) enfatiza que o trabalho desenvolvido pelo funcionário (a) do atendimento é uma atividade de mediação entre as finalidades da instituição e objetivos dos usuários.

\subsection{Satisfação e Qualidade}

Para Kotler (1996) "satisfação é o nível de sentimento de uma pessoa resultante da comparação do desempenho (ou resultado) de um produto em relação a suas expectativas". Ele reforça que "satisfação é o sentimento de prazer ou de desapontamento resultante da comparação do desempenho esperado pelo produto (ou resultado) em relação às expectativas da pessoa" (1998).

Conforme Wilkie (1994 apud BEBER, 1999), a satisfação e insatisfação refere-se a uma resposta emocional para uma avaliação de consumo de um produto ou serviço.

$\mathrm{O}$ ponto fundamental da prestação de serviços é atender às necessidades do cliente. Lovelock e Wright (2003, p.102) afirmam que:
produtividade e qualidade foram historicamente consideradas como questões para os gerentes de operações. Entretanto, os esforços contínuos para compreender e melhorar a qualidade voltavam-se ao cliente e ao reconhecimento de que a qualidade é definida pelo cliente.

Ainda conforme este autor, a qualidade de serviços é o grau em que o serviço atende ou supera as expectativas do cliente. E que as definições baseadas em serviços em sua maioria igualam qualidade à satisfação do cliente, conforme a seguinte fórmula:

\section{SATISFAÇÃO = SERVIÇO PERCEBIDO/SERVIÇO ESPERADO}

$\mathrm{O}$ autor enfatiza que, se os clientes perceberem a entrega efetiva dos serviços como melhor do que o esperado ficarão contentes; se ela estiver abaixo das expectativas, ficarão enraivecidos e julgarão a qualidade de acordo com seu grau de satisfação com o serviço. 
Conforme Marshall Júnior et al. (2006),

qualidade é um processo intrínseco a qualquer situação de uso de algo tangível, a relacionamentos envolvidos na prestação de um serviço ou a percepções associadas a produtos de natureza intelectual, artística, emocional e vivencial.

Segundo Granuzzo et. al. (2000) O termo "qualidade", na linguagem corrente, tem significados distintos. Entretanto é possível observar que a qualidade de um produto ou serviço está ligada diretamente à satisfação total do cliente e é obtida através do equilíbrio entre três fatores: qualidade intrínseca, custo e atendimento (qualidade certa, no local certo e no tempo certo).

Para Soares (1994), “qualidade em serviços significa atender as reais necessidades dos clientes, sejam elas explícitas ou implícitas dentro do prazo que o cliente deseja e a um justo valor".

Segundo Amaral et al. (2002), a qualidade em serviços é um elemento crítico na determinação da competitividade entre as empresas: aquelas que garantirem os mais elevados níveis de satisfação aos seus clientes estarão diferenciando-se no mercado e construindo uma vantagem competitiva frente às empresas concorrentes.

As tendências apontam para a qualidade dos serviços como estratégia empresarial capaz de conquistar novos clientes e manter os antigos.

\footnotetext{
Uma das maiores tendências mundiais tem sido o impressionante crescimento dos serviços como resultados da maior riqueza, de mais tempo de lazer e do crescimento da complexidade dos produtos que requerem serviços (KOTLER; ARMSTRONG, 2001, p. 224).
}

Segundo Gianesi e Corrêa (1994), existe uma avaliação da qualidade feita pelo cliente durante ou após o término do processo de prestação do serviço, que se dá por meio da comparação entre o que o cliente esperava do serviço e o que ele percebe do serviço prestado.

Combinando a visão de diferentes autores, para avaliar a qualidade, eles propõem um conjunto de critérios de avaliação do serviço:

a) Tangíveis: refere-se à qualidade e ou a aparência de qualquer evidência física do serviço ou do sistema de operações.

b) Consistência: conformidade com experiência anterior, ausência de variabilidade no resultado ou no processo.

c) Competência: refere-se à habilidade e ao conhecimento do fornecedor para executar o serviço, relacionando-se às necessidades "técnicas" dos consumidores. 
d) Velocidade no atendimento: é um critério importante para a maioria dos consumidores de serviços, notadamente quando a presença do cliente é necessária.

e) Atendimento/atmosfera: é o critério que avalia o prazer que o cliente tem em participar ou estar presente no processo de prestação do serviço.

f) Flexibilidade: significa ser capaz de mudar e se adaptar rapidamente à operação devido a mudanças e necessidades dos clientes, no processo ou no suprimento de recursos.

g) Credibilidade/segurança: refere-se a uma baixa percepção de risco no cliente e a habilidade de transmitir confiança.

h) Acesso: avalia a facilidade que o cliente tem em entrar em contato com o fornecedor do serviço.

i) Custo: é o critério que avalia quanto o consumidor irá pagar, em moeda, por determinado serviço.

Grönroos (1993) afirma que uma boa qualidade percebida é obtida quando a qualidade experimentada atende às expectativas do cliente, ou seja, à qualidade esperada. Portanto, o processo de avaliação da qualidade de serviços que o cliente faz está em função de suas expectativas (qualidade esperada) e de sua percepção do serviço (qualidade experimentada).

Para Parasuraman, Zeithaml e Berry (1988 apud MARCHETTI, 2001 p. 58) citam que a qualidade percebida e satisfação do cliente são construtos que se relacionam e que a partir dos incidentes de satisfação que ocoreem ao longo do tempo, a percepção da qualidade é formada.

Conforme Amaral (2002), tendo definido qualidade, o desafio se encontra em como gerenciá-la e ser consistente na sua entrega. Há uma necessidade de modelos que permitam a gerência identificar os desvios da qualidade e planejar a construção de um programa de melhoria da qualidade dos serviços e

uma correta gestão da qualidade dos serviços será a responsável por produzir um pacote de valor que gere níveis de satisfações que garantam que o cliente fique fidelizado. Um cliente fiel será um cliente retido, freqüente, que, mais do que apenas voltar, será um agente de marketing da empresa, fazendo propaganda boca a boca e divulgando sua satisfação... (CORRÊA e CAON, 2002, p. 87). 
Segundo Carlzon (2005), o mais importante na prestação de serviço acontece nos momentos da verdade, e eles não devem ser negligenciados. Ele chamou de "hora da verdade" o momento em que o cliente entra em contato com o pessoal da linha de frente: é nessas ocasiões que ele forma sua imagem da empresa e é essa experiência que o faz voltar ou não a procurar os seus serviços.

Para Albrecht (1998) o termo "hora da verdade" define qualquer episódio no qual o cliente entra em contato com qualquer aspecto da organização e obtém uma impressão da qualidade.

Grönroos (1993) afirma que os momentos da verdade podem ser considerados verdadeiros "momentos de oportunidade", pois representam para o prestador de serviço demonstrar ao cliente a qualidade de seus serviços. É quando o cliente "sente" o serviço acontecendo.

Existe uma tentativa, amplamente aceita, para avaliar a qualidade dos serviços oferecidos, que é o modelo sugerido por Zeithaml, Parassunamam e Berry (1990 apud AMARAL, 2002), que mostra as principais atividades das organizações de serviços que influenciam na percepção da qualidade. $\mathrm{O}$ modelo mostra as interações entre essas atividades e identifica as conexões entre as atividades-chave do provedor do serviço, que são relevantes para o oferecimento de um nível satisfatório de qualidade. As conexões são descritas como gaps ou discrepâncias; um gap representa um obstáculo para alcançar um nível satisfatório de qualidade do serviço.

Os gaps a que se refere o modelo são os seguintes apresentados resumidamente por Amaral (2002, p. 45):

a) Expectativa dos clientes - percepção da gerência (Gap 1): a gerência pode ter percepções imprecisas sobre as expectativas dos clientes.

b) Especificação da qualidade do serviço (Gap 2): pode haver falta de habilidade por parte da gerência em traduzir as expectativas dos clientes em especificações de qualidade dos serviços.

c) Execução do serviço (Gap 3): as razões para as discrepâncias são a falta de suporte adequado para o pessoal de linha de frente, problemas de processos ou variabilidade de performance nos momentos de contato com os clientes. Isso resulta na percepção de serviço de qualidade inferior.

d) Comunicação externa (Gap 4): a expectativa dos clientes é influenciada pela comunicação da empresa. Uma organização de serviços precisa garantir que seus esforços e materiais de marketing e promoção descrevam precisamente os serviços oferecidos além da forma como são prestados. 
e) Serviço esperado - serviço percebido (Gap 5): a qualidade percebida de um serviço depende do tamanho da lacuna entre o serviço esperado e o percebido, que, por outro lado, depende da intensidade dos demais gaps.

Amaral et al. (2002) afirmam que o modelo descrito acima é uma ferramenta de diagnóstico, que se usado corretamente permite à gerência a identificação das falhas na qualidade dos serviços.

Segundo Parassunaman et al. (1985 apud MIGUEL, SALOMI, 2004) o modelo pode ser representado da seguinte forma:

\section{Figura 1 - Modelo de Qualidade dos Serviços}

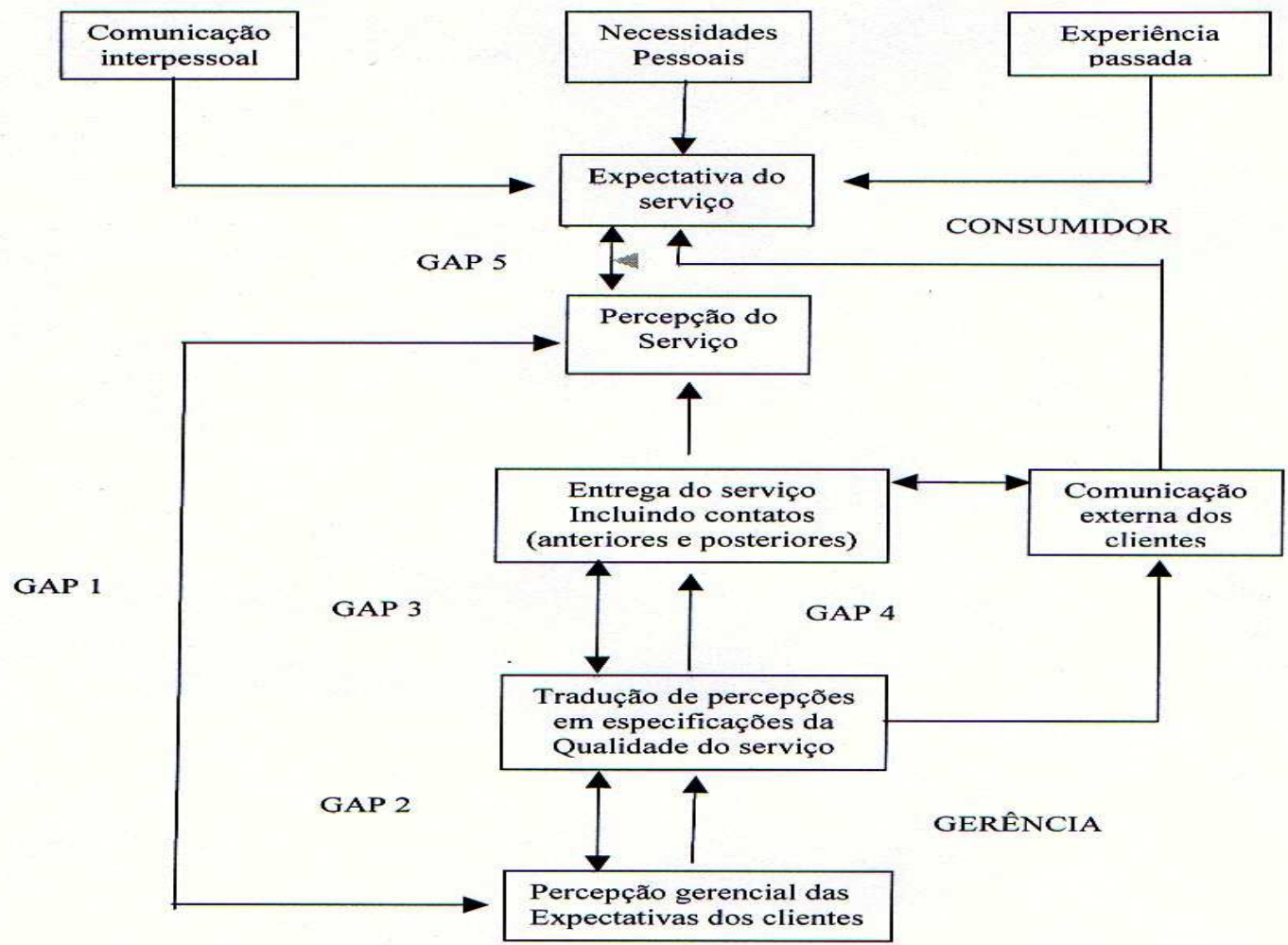

Fonte: Parasuraman et al. (1985 apud MIGUEL; SALOMI, 2004, p.16).

Segundo Holey et al. (2001 apud PEREIRA, 2005), há diferenças entre o serviço que o cliente deseja obter e o que de fato ele obtém do fornecedor, existindo três níveis de tolerância que exprimem o quanto o consumidor ficou satisfeito com a empresa e, ainda, relacionam este nível de satisfação com o grau de probabilidade de obter a lealdade do mesmo, diante da ultrapassagem positiva do nível de tolerância. O serviço adequado é aquele que satisfaz o cliente, ele encontra o mínimo aceitável, sem se julgar insatisfeito. O serviço desejado é aquele que encanta o cliente, pois excedeu as suas expectativas. Entre o serviço adequado e o serviço desejado há uma zona de tolerância. 
Segundo Parasuraman et al. (1985 apud MIGUEL e SALOMI, 2004) os determinantes da qualidade são os listados no quadro a seguir:

Quadro 1 - Determinantes da qualidade (PARASURAMAN e al., 1985).

\begin{tabular}{|c|c|}
\hline DETERMINANTE & CONCEITO \\
\hline Confiabilidade & $\begin{array}{l}\text { Abrange consistência de desempenho e confiabilidade. Também significa que a } \\
\text { empresa honra seus compromissos. Especificamente envolve: precisão nas contas, } \\
\text { manutenção dos registros de forma correta e realização dos serviços no tempo } \\
\text { indignado. }\end{array}$ \\
\hline Presteza & $\begin{array}{l}\text { Refere-se ao desejo e presteza que os empregados têm em prover os serviços. } \\
\text { Envolve rapidez nos serviços. }\end{array}$ \\
\hline Competência & $\begin{array}{l}\text { Significa possuir as habilidades necessárias e conhecimento para realizar o } \\
\text { serviço, envolvendo conhecimento e habilidade do pessoal de atendimento, } \\
\text { conhecimento e habilidade do pessoal de apoio operacional, capacidade de } \\
\text { pesquisa de organização. }\end{array}$ \\
\hline Acessibilidade & $\begin{array}{l}\text { Refere-se à proximidade e a facilidade de contato, significando que: o serviço } \\
\text { pode ser acessível por telefone, o tempo de espera para receber o serviço não é } \\
\text { muito extenso, tem um horário de funcionamento e localização conveniente. }\end{array}$ \\
\hline Cortesia & $\begin{array}{l}\text { Abrange educação, respeito, consideração e amabilidade do pessoal de } \\
\text { atendimento. Compreende também consideração com a propriedade do cliente. }\end{array}$ \\
\hline Comu & $\begin{array}{l}\text { Significa manter os clientes informados em linguagem que sejam capazes de } \\
\text { compreender; pode significar que a companhia deve ajustar sua linguagem para } \\
\text { diferentes consumidores, aumentando o nível e sofisticação para os mais bem } \\
\text { educados e conversando de maneira simples e direta com os mais simples. } \\
\text { Também compreende: proporcionar explicação do serviço, preços, descontos e } \\
\text { garantir ao consumidor que um eventual problema será resolvido. }\end{array}$ \\
\hline Credibilidade & $\begin{array}{l}\text { Considera a honestidade e implica em que a empresa esteja comprometida em } \\
\text { atender aos interesses e objetivos dos clientes, abrange: nome e reputação da } \\
\text { empresa, características pessoais dos atendentes e nível de interação com os } \\
\text { clientes durante a venda. }\end{array}$ \\
\hline Segurança & $\begin{array}{l}\text { Ausência de perigo, risco ou dúvidas, abrangendo: segurança física, financeira e } \\
\text { confidencialidade. }\end{array}$ \\
\hline $\begin{array}{l}\text { Compreensão e } \\
\text { Conhecimento do cliente }\end{array}$ & $\begin{array}{l}\text { Significa esforçar-se para compreender as necessidades dos clientes, envolvendo: } \\
\text { aprendizado sobre os requisitos específicos do cliente, proporcionar atenção } \\
\text { individualizada, reconhecer clientes constantes e preferenciais. }\end{array}$ \\
\hline Aspectos Tangíveis & $\begin{array}{l}\text { Significa a inclusão e demonstração de evidências físicas ao serviço, tais como } \\
\text { instalações, aparência do pessoal, ferramentas e equipamentos utilizados no } \\
\text { serviço, representação física do serviço, tais como um cartão de crédito plástico, } \\
\text { ou uma prestação de contas, além de outros clientes presentes nas instalações. }\end{array}$ \\
\hline
\end{tabular}

Fonte: MIGUEL e SALOMI, 2004.

Segundo Pereira e Farias (2005), o ponto chave da qualidade de prestação de um serviço é atender ou superar as expectativas do cliente, levando-se em conta os diversos fatores que interferem na sua formação e os níveis dessas expectativas, bem como os critérios de julgamento da qualidade dos serviços.

Segundo Lovelock (2001, p. 108-109), existem sete lacunas que potencializam a qualidade do serviço: 
a) lacuna no conhecimento: a diferença entre o que os fornecedores de serviço acreditam que os clientes esperam e as necessidades e expectativas reais dos clientes.

b) lacuna nos padrões: a diferença entre percepções da administração sobre as expectativas do cliente e os padrões de qualidade estabelecidos para entrega do serviço;

c) lacuna na entrega: a diferença entre padrões de entrega especificados e o desempenho real do fornecedor de serviços.

d) lacuna nas comunicações internas: a diferença entre aquilo que o pessoal de propaganda e vendas julga que são características do produto e, desempenho e nível de qualidade do serviço e aquilo que a organização é capaz de entregar.

e) lacuna nas percepções: a diferença entre o que é entregue e o que os clientes percebem ter recebido.

f) lacuna na interpretação: a diferença entre aquilo que as campanhas de comunicação de um fornecedor de serviço realmente prometem e aquilo que um cliente acha que foi prometido por essas comunicações.

g) lacuna no serviço: a diferença entre o que os clientes esperam receber e suas percepções do serviço que é realmente entregue.

\subsection{A preocupação com a Qualidade no Serviço Público}

O termo qualidade origina-se do latim qualitas; qualitatem e por definição de acordo com KOOGAN \& HOUAISS (1994), refere-se à superioridade, excelência em qualquer coisa. Portanto, entende-se qualidade como excelência na prestação de serviços.

Segundo DENTON (1990 apud OLIVEIRA, 2003), prestar serviços com qualidade é, sobretudo, uma questão cultural. Cabe às organizações que optarem pela incorporação de tais valores ao seu ambiente de trabalho a criação de mecanismos que garantam a qualidade dos serviços que prestam. A incorporação de uma filosofia de serviços com qualidade só ocorre se a administração central adotá-la como prioridade, traduzida mais em ações do que em palavras. E conclui que, a qualidade em produtos e serviços resulta, essencialmente, das ações e do trabalho humano.

Segundo Ferreira (2000), a qualidade do serviço de atendimento ao público condizente com a realidade brasileira, apresenta-se como um desafio institucional que exige transformações urgentes.Essa necessidade se apresenta sob múltiplas facetas, entre elas as freqüentes queixas dos usuários.

As ações para a qualidade dos serviços públicos, conforme Brasil (1997 apud OLIVEIRA, 2003, p. 69), devem estar centradas no perfil do usuário e em suas 
aspirações, gerando indicadores de desempenho e a necessidade de "fazer certo da primeira vez", como tarefa essencial das organizações e de seus servidores.

No que se refere à qualidade total nos serviços públicos Wood Jr. e Urdam (1994 apud SPILK, 2004 p. 45), apontam que em decorrência de déficits orçamentários e escassez de recursos, os administradores do governo têm buscado soluções administrativas para a melhoria dos serviços públicos. Os autores ressaltaram que muitos estudiosos consideravam a filosofia do método da qualidade total incompatível com as organizações públicas. Porém, essa idéia foi mudando em decorrência de importantes demandas, como: aumento da produtividade, envolvimento do usuário, atribuição de maior poder decisório aos funcionários, necessidade de medir e divulgar o desempenho e desenvolver planos estratégicos de longo prazo.

O desafio de prestar serviços com qualidade vem sendo assimilado gradativamente pelo serviço público.

Segundo Oliveira (2003), alguns prêmios de incentivo à qualidade nos, foram criados ao longo da década de 90 no serviço público.

- Em 1990, foi instituído o Prêmio Nacional de Qualidade - PNQ que visava reconhecer a excelência de gestão de organizações brasileiras, promovendo o entendimento referente aos requisitos para excelência do desempenho, troca de informações quanto a métodos e técnicas de gestão de sucesso. Continha cinco categorias de premiação: grandes empresas, médias empresas, pequenas e microempresas, organização sem fins lucrativos e órgãos da Administração Pública.

- Em 1998, foi instituído o Prêmio Qualidade do Governo Federal - PQGF, como um sistema de premiação intermediário ao PNQ, que teve como primeira ação à adaptação de organizações governamentais às especificidades da Administração Pública. Esse prêmio tem como destino os órgãos públicos da administração direta, autarquias fundações, empresas públicas, sociedades de economia mista, organizações sociais e instituições vinculadas ao Poder Executivo, nos níveis federal, estadual e municipal.

Segundo consta em BRASIL (2009), em 2005 foi instituída a mais recente iniciativa do governo federal: o GesPública.

O Programa Nacional de Gestão Pública e Desburocratização - GesPública foi instituído pelo Decreto $\mathrm{n}^{\circ} 5.378$, de 23 de fevereiro de 2005, com a finalidade de 
contribuir para a melhoria da qualidade dos serviços públicos prestados aos cidadãos e para o aumento da competitividade do País, formulando e implementando medidas integradas em agenda de transformações da gestão, necessárias à promoção dos resultados preconizados no plano plurianual, à consolidação da administração pública profissional, voltada ao interesse do cidadão e à aplicação de instrumentos e abordagens gerenciais.

O GesPública é a fusão dos Programas da Qualidade no Serviço Público (PQSP) e o Programa Nacional de Desburocratização. O GesPública é a mais arrojada política pública formulada para a gestão. Esta afirmação está baseada em três características:

$\checkmark$ Essencialmente pública: é uma política formulada a partir da premissa de que a gestão de órgãos e entidades públicos pode e deve ser excelente, pode e deve ser comparada com padrões internacionais de qualidade em gestão, mas não pode nem deve deixar de ser pública. A qualidade da gestão pública tem que ser orientada para o cidadão, e desenvolver-se dentro do espaço constitucional demarcado pelos princípios da impessoalidade, da legalidade, da moralidade, da publicidade e da eficiência.

$\checkmark \quad$ Focada em resultados: sair do serviço à burocracia e colocá-la a serviço do resultado tem sido o grande desafio do GesPública e dos programas que o precederam. Entenda-se por resultado para o setor público o atendimento total ou parcial das demandas da sociedade traduzidas pelos governos em políticas públicas. Neste sentido, a eficiência e a eficácia serão tão positivas quanto à capacidade que terão de produzir mais e melhores resultados para o cidadão (impacto na melhoria da qualidade de vida).

Federativa: a base conceitual e os instrumentos do GesPública não estão limitados a um objeto específico a ser gerenciado (saúde, educação, previdência, saneamento, tributação, fiscalização etc). Aplicam-se a toda a administração pública em todos os poderes e esferas de governo.

Diante de algumas iniciativas citadas acima, pode-se depreender que a qualidade no serviço público é viável e essencial para as organizações públicas.

O caminho para alcançar a qualidade é difícil, mas com a aplicação correta dos programas de qualidades, é possível chegar a bons resultados, e diante destes repensar a organização, propondo mudanças, se necessárias, que futuramente se revelem por meio da melhoria na prestação dos serviços.

Primar pela qualidade é um desafio que deve ser superado a cada dia. O setor público precisa ser flexível e adaptável às mudanças e exigências da sociedade contemporânea. 


\section{METODOLOGIA}

A metodologia tem como objetivo especificar como a pesquisa foi desenvolvida. Neste capítulo é descrita a metodologia, o tipo de pesquisa, universo e amostra, técnica, instrumento e procedimentos de coleta e análise de dados, e a unidade objeto desta pesquisa é caracterizada.

\subsection{Tipo de pesquisa}

Para Vergara (2000) a pesquisa pode ser classificada quanto aos fins a que se destina e quanto aos meios de investigação.

Quanto aos fins, a pesquisa realizada foi do tipo descritiva de caráter quantitativo, e quanto aos meios trata-se de um estudo de caso desenvolvido na Universidade de Brasília $(\mathrm{UnB})$.

\subsection{Universo e Amostra da pesquisa}

A amostra considerada na pesquisa foi do tipo não-probalística por acessibilidade da pesquisadora.

Participaram da coleta 200 alunos de graduação da Universidade de Brasília em um universo de aproximadamente 26.000 alunos-usuários da Secretaria de Assuntos Acadêmicos (SAA).

O universo, segundo Mattar (1996), é o agregado de todos os casos que se enquadram num conjunto de especificações previamente estabelecidas. Ao se definir um universo é preciso que se leve em conta também o elemento de pesquisa, ou seja, a unidade sobre a qual se procura obter os dados, a unidade amostral, a abrangência e o período de tempo.

\subsection{Técnica e instrumento da coleta de dados}

Para medir a diferença entre o serviço esperado e o desempenho, que será traduzido na qualidade dos serviços, foi utilizada a escala SERVQUAL (Service Quality), pois esta, segundo Hercos e Berzovsky (2006), permite avaliar cinco dimensões da qualidade de serviço.

Parasuraman, Zeithaml e Berry (1988 apud CUNHA, 2004), desenvolveram a escala Servqual para mensuração das percepções dos clientes sobre a qualidade de serviços. É 
uma escala multidimensional que foi testada quanto à fidedignidade e validade pelos autores, sendo aplicável às organizações do setor de serviços. A SERVQUAL é composta por cinco dimensões:

- Aspectos tangíveis (aparência física das instalações, equipamentos, pessoal e material de comunicação).

- Confiabilidade (desempenhar o serviço prometido de modo confiável e preciso).

- Presteza (disposição de ajudar aos clientes e fornecer o serviço com presteza).

- Empatia (atenção individualizada proporcionada aos clientes);

- Segurança (conhecimento, capacidade dos funcionários de transmitir confiança).

Segundo Machado (1999 apud PEREIRA; FARIAS 2005 p.5) a escala SERVQUAL original consiste em um questionário elaborado em duas seções: uma correspondente às expectativas e outra que busca medir o julgamento do cliente sobre o serviço prestado pela organização que está sendo avaliada.

Essa escala conforme Pereira e Farias (2005 p. 5), pode e deve ser adaptada às variáveis específicas do serviço a ser medido, dessa forma, tais adequações podem vir no tamanho do instrumento, na quantidade de dimensões, variáveis ou indicadores, e ainda, no nível de pontuação da escala.

O instrumento avalia as cinco dimensões de qualidade de serviço, em uma escala que varia de 1 a 7 pontos, e cada dimensão é composta por 4 a 5 itens.

As escalas de opinião, do tipo Likert, que foram utilizadas para mensurar as características dos quesitos expectativas e percepções, seguiram a seguinte classificação, conforme os pesos que lhe foram atribuídas:

Rodrigues (2001), afirma que a escala SERVQUAL recebeu algumas críticas referentes tanto ao seu conceito quanto a sua metodologia.

Para Freitas et. al. (2008), apesar das críticas e deficiências creditadas à escala SERVQUAL, é inquestionável o seu impacto no âmbito da avaliação da qualidade de serviços, sendo o modelo mais amplamente aplicado em diversos setores, com resultados positivos, satisfatórios e práticos. 
Tabela 1 - Escore das escalas de opinião utilizada no instrumento SERVQUAL

\begin{tabular}{|l|l|l|}
\hline \multicolumn{1}{|c|}{ Pesos } & \multicolumn{2}{|c|}{ FASES DA PESQUISA } \\
\hline & Expectativas & Percepções \\
\hline 1 & Não é importante & Péssimo (não atende às expectativas) \\
\hline 2 & Pouco importante & Ruim \\
\hline 3 & Relativamente importante & Regular \\
\hline 4 & Importante & Bom \\
\hline 5 & Bem importante & Muito Bom \\
\hline 6 & Muito importante & Ótimo \\
\hline 7 & $\begin{array}{l}\text { Extremamente importante } \\
\text { (imprescindível) }\end{array}$ & Excelente (atende plenamente às expectativas) \\
\hline
\end{tabular}

Foram aplicados três instrumentos de coleta: por meio do primeiro se analisou o grau de expectativa do usuário e do segundo o grau de percepção do usuário em relação à qualidade dos serviços oferecidos pela SAA. O terceiro foi aplicado com o objetivo de identificar o perfil do usuário destes serviços.

O instrumento de coleta foi aplicado entre março e abril/09 na Universidade de Brasília - Campus Universitário Darcy Ribeiro, por concentrar a grande maioria dos alunos da Universidade e ser de fácil acesso à pesquisadora. A abordagem aos pesquisados ocorreu de forma tranqüila e cordial, tendo como base o diálogo no intuito de melhor informar sobre a pesquisa de cunho acadêmico, que tinha como abordagem os serviços prestados pela SAA.

\subsection{Procedimentos de análise dos dados}

Para atingir os objetivos propostos nesta pesquisa foi utilizado o Método da Análise descritiva dos dados. Essa análise foi feita com o auxílio do software EXCEL, para calcular as médias ponderadas para verificação dos gaps.

O objetivo de uma análise de dados é sumarizar as observações depois do processamento de dados, com condições que permitam obter as respostas aos problemas da pesquisa, devendo procurar identificar elementos como: caracterizar o que é, ou não, típico no grupo estudado; mostra outros aspectos da maneira pela qual os indivíduos se distribuem com relação à variável que está sendo medida e a relação entre diferentes variáveis, bem como descrever as diferenças entre dois ou mais grupos de indivíduos.

Segundo Amaral et al. (2002), existem três interpretações para os resultados da qualidade em relação aos gaps em cada afirmativa:

Expectativas < Percepções: qualidade satisfatória. 
Expectativas $=$ Percepções: qualidade satisfatória ou qualidade percebida aceitável.

Expectativas > Percepções: qualidade percebida é insatisfatória/inaceitável.

O cálculo de médias ponderadas para verificação dos gaps foi encontrado a partir da fórmula a seguir:

Figura 2 - Fórmula para o cálculo dos Gaps de Qualidade dos Serviços

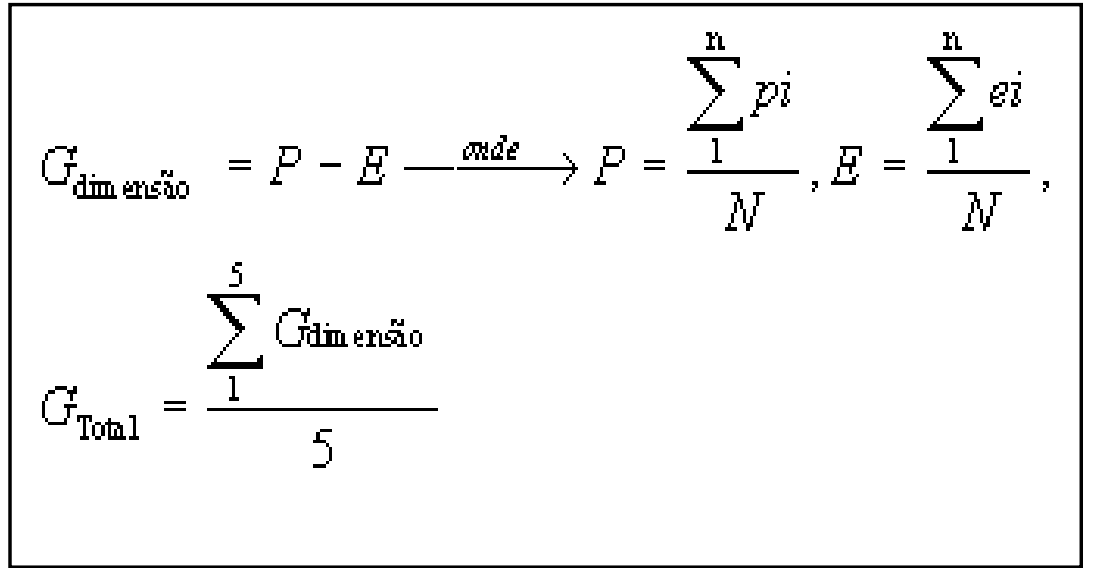

Fonte: Parasuraman; Berry; Zeithaml (1988, apud PEREIRA e FARIAS, 2005, p. 7).

Onde:

$\mathrm{G}=$ gap/hiato

$\mathrm{E}=$ expectativa

$\mathrm{P}=$ percepção

$\mathrm{N}=$ total de observações/entrevistados

$\mathrm{n}=$ total de ocorrências para cada peso da escala

\subsection{Caracterização da unidade pesquisada}

Secretaria de Administração Acadêmica (SAA) é um órgão de execução diretamente vinculado à Vice-Reitoria (VRT).

A SAA é responsável pelo registro de todos os estudantes admitidos, incluindo-os no cadastro discente da UnB, em seus respectivos sistemas: graduação, pós-graduação e extensão.

A SAA responde, ainda, pela execução de todas as rotinas acadêmicas, pela expedição de documentos acadêmicos, atestados, certificados, diplomas, matrícula e, também, pelo registro e pelo controle de todas as atividades acadêmicas da Universidade.

Para melhor atender os estudantes, a SAA instituiu os Postos Avançados (unidades administrativas localizadas no espaço físico das unidades acadêmicas, onde os 
alunos estudam). As informações sobre eventos acadêmicos e sobre documentos de natureza escolar podem ser obtidas nos Postos Avançados da SAA, nas unidades acadêmicas. Os postos estão distribuídos da seguinte forma:

\section{Cursos diurnos}

- Posto da SAA no ICC Centro, localizado no Instituto de Ciências Exatas: atende alunos das seguintes unidades acadêmicas: Instituto de Ciências Exatas/ Instituto de Letras / Instituto de Física / Departamento de Estatística / Departamento de Matemática (IE/IL/IF/EST/MAT).

- Posto da SAA no ICC Sul, localizado no Instituto de Ciências Biológicas: atende alunos das seguintes unidades acadêmicas: Instituto de Ciências Biológicas / Instituto de Psicologia / Instituto de Química/ Faculdade de Agronomia e Medicina Veterinária (IB/IP/IQ/FAV).

- Posto da SAA no ICC Norte, localizado no Instituto de Ciências Humanas: atende alunos do Instituto de Ciências Humanas (IH).

- Posto da SAA no ICC Norte, localizado na Faculdade de Arquitetura e Urbanismo: atende alunos das seguintes unidades acadêmicas: Faculdade de Comunicação / Faculdade de Arquitetura e Urbanismo / Instituto de Geologia / Departamento de Ciência da Computação (FAC/FAU/IG/CIC).

- Posto da SAA localizado na Faculdade de Tecnologia: atende aluno da Faculdade de Tecnologia (FT).

- Posto da SAA localizado na Faculdade de Medicina e de Ciências da Saúde: atende alunos das seguintes unidades acadêmicas: Faculdade de Ciências da Saúde / Faculdade de Medicina/ Faculdade de Educação Física (FS/FMD/FEF).

- Posto da SAA localizado na Faculdade de Direito: atende alunos das seguintes unidades acadêmicas: Faculdade de Direito / Faculdade de Economia, Administração, Contabilidade e Ciência da Informação e Documentação / Instituto de Ciências Políticas e Instituto de Relações Internacionais (FD/FACE/IPOL/IREL).

- Posto da SAA localizado na Faculdade de Educação: atende alunos das seguintes unidades acadêmicas: Faculdade de Educação / Instituto de Artes (FE/IdA). 


\section{Cursos Noturnos}

- Posto da SAA localizado no Mezanino da entrada do ICC Norte. Atende alunos do noturno das seguintes unidades acadêmicas: Instituto de Ciências Exatas / Instituto de Ciências Biológicas / Instituto de Letras / Faculdade de Economia, Administração, Contabilidade e Ciência da Informação e Documentação (IE/IB/IL/FACE).

- Posto da SAA localizado na Faculdade de Educação: atende alunos do noturno das seguintes unidades acadêmicas: Faculdade de Educação /Instituto de Artes (FE/IdA). 


\section{APRESENTAÇÃO E DISCUSSÃO DOS RESULTADOS}

Nesse capítulo são apresentadas a análise e a discussão dos resultados da pesquisa, obtidos a partir da tabulação dos dados e seleção dos aspectos significativos que visam atender os objetivos propostos nesta pesquisa: verificar o grau de expectativa do usuário em relação aos serviços recebidos, identificar o grau de satisfação do usuário em relação aos serviços recebidos e conhecer a diferença (gap) entre a expectativa e o desempenho da instituição com relação aos serviços prestados pela Secretaria de Assuntos Acadêmicos (SAA).

\subsection{Perfil dos alunos-usuários}

Um dos objetivos desta pesquisa foi identificar o perfil do aluno-usuário dos serviços prestados pela SAA e, para tanto, foram consideradas as variáveis: sexo, idade, estado civil, tempo de permanência na Universidade, se foi ou ainda é aluno de outra universidade, situação profissional, renda familiar e curso de graduação no qual está matriculado.

Quanto ao sexo, os respondentes foram $44 \%$ do sexo feminino e $56 \%$ do sexo masculino, ou seja, um percentual de $12 \%$ de diferença.

Em relação à distribuição e frequência a faixa etária que apresentou maior número de respondentes (47\%) foi entre 18 e 20 anos. E a faixa etária que apresentou menor número de respondentes (3\%) foi acima de 41 anos.

Quanto ao tempo de permanência na Universidade, as distribuições e frequências que apresentaram maior número de respondentes - $28 \%$ e $25 \%$ - foram dos respondentes que estão na Universidade há 01 e 03 anos, respectivamente. E a distribuição e frequência que apresentou menor número de respondentes $(1 \%)$ foi a dos alunos que estão na Universidade há mais de 07 anos.

Quanto ao estado civil, 82\% responderam serem solteiros (as), 15\% casados (as), $2 \%$ divorciados (as) e apenas $1 \%$ viúvos (as).

Dos 200 alunos-usuários pesquisados, 77\% responderam serem alunos somente da Universidade de Brasília, ou seja, sem nenhuma experiência com outra instituição de ensino superior. E 13\% responderam que já estudaram ou estudam também em outra instituição.

Quanto ao vínculo empregatício, $48 \%$ responderam serem apenas estudantes, $32 \%$ são vinculados a alguma organização como funcionários e $20 \%$ são estagiários. 
Quanto à renda familiar, 55,5\% possuem renda familiar acima de $\mathrm{R} \$ 3.500,00$ (três mil e quinhentos reais) e apenas $1 \%$, possui renda familiar abaixo de $\mathrm{R} \$ 500,00$ (quinhentos reais).

Em relação aos cursos, o maior número de respondentes (30\%) são alunos de Administração e o menor número dos respondentes (0,5\%) é do curso de Música. Os demais pesquisados foram dos cursos de Agronomia, Arquitetura, Biologia, Ciências Contábeis, Comunicação Social, Direito, Educação Física, Enfermagem, Engenharia Civil, Engenharia de Redes, Engenharia Elétrica, Engenharia Florestal, Engenharia Mecatrônica, Engenharia Mecânica, Filosofia, Física, Geografia, Geologia, História, Letras, Pedagogia, Psicologia, Ciência da Computação, Economia, Ciência Política, Química, Matemática e Sociologia.

\subsection{Avaliação das EXPECTATIVAS e PERCEPÇÕES do aluno-usuário quanto à qualidade dos serviços oferecidos pela SAA}

Conforme Lovelock e Wright (2003, p.107), os clientes possuem uma expectativa quanto à qualidade do serviço, com base em necessidades individuais, experiências passadas, recomendações de terceiros e propagandas de um fornecedor de serviços. E os desempenhos dos serviços que surpreendem e encantam os clientes por ficarem acima dos seus níveis de serviço desejado serão vistos como de qualidade superior. Se a entrega do serviço cair dentro de sua zona de tolerância, acharão que ele é adequado. Mas se a qualidade real cai abaixo do nível de serviço adequado esperado pelos clientes, ocorrerá uma discrepância entre o desempenho do fornecedor de serviços e a expectativa do cliente.

Segundo Zeithaml et al. (1990, apud ELEUTÉRIO, 2002), não basta compreender a importância de fornecer serviços com excelente qualidade: é preciso que haja um processo contínuo de monitoramento das percepções dos clientes sobre a qualidade do serviço, identificação das causas das discrepâncias encontradas e adoção de mecanismos adequados para a melhoria.

A seguir serão apresentadas as análises das cinco dimensões separadamente, segundo os dados obtidos na pesquisa. 


\subsubsection{Aspectos Tangíveis}

Tabela 2 - Distribuição das respostas de acordo com a frequência.

\begin{tabular}{l|c|c|c|c|c|c|c}
\hline EXPECTATIVA & $\mathbf{1}$ & $\mathbf{2}$ & $\mathbf{3}$ & $\mathbf{4}$ & $\mathbf{5}$ & $\mathbf{6}$ & $\mathbf{7}$ \\
\hline $\begin{array}{l}\text { Instalações físicas adequadas (confortáveis, arejadas, } \\
\text { limpas, iluminadas e silenciosas). }\end{array}$ & 0 & 6 & 29 & 38 & 37 & 49 & 41 \\
\hline $\begin{array}{l}\text { Equipamentos modernos que possam facilitar o processo } \\
\text { de atendimento }\end{array}$ & 1 & 6 & 10 & 27 & 40 & 50 & 66 \\
\hline $\begin{array}{l}\text { Localização dos Postos avançados de atendimento } \\
\text { adequado às necessidades }\end{array}$ & 0 & 2 & 13 & 27 & 37 & 53 & 68 \\
\hline Quantidade suficiente de colaboradores para atendimento & 4 & 4 & 12 & 13 & 35 & 48 & 84 \\
\hline
\end{tabular}

Fonte: Pesquisa de campo, 2009.

Tabela 3 - Distribuição das respostas de acordo com a frequência.

\begin{tabular}{l|c|c|c|c|c|c|c}
\hline PERCEPÇÃO & $\mathbf{1}$ & $\mathbf{2}$ & $\mathbf{3}$ & $\mathbf{4}$ & $\mathbf{5}$ & $\mathbf{6}$ & $\mathbf{7}$ \\
\hline $\begin{array}{l}\text { Instalações físicas adequadas (confortáveis, arejadas, } \\
\text { limpas, iluminadas e silenciosas). }\end{array}$ & 5 & 24 & 56 & 64 & 38 & 9 & 4 \\
\hline $\begin{array}{l}\text { Equipamentos modernos que possam facilitar o processo } \\
\text { de atendimento }\end{array}$ & 12 & 24 & 57 & 60 & 31 & 10 & 6 \\
\hline $\begin{array}{l}\text { Localização dos Postos avançados de atendimento } \\
\text { adequado às necessidades }\end{array}$ & 6 & 25 & 34 & 60 & 38 & 24 & 13 \\
\hline Quantidade suficiente de colaboradores para atendimento & 11 & 22 & 46 & 57 & 35 & 23 & 6 \\
\hline
\end{tabular}

Fonte: Pesquisa de campo, 2009.

Tabela 4 - Médias obtidas na dimensão Aspectos Tangíveis

\begin{tabular}{|c|c|c|c|}
\hline Itens de medição dos aspectos tangíveis & Expectativas & Percepções & Gaps \\
\hline $\begin{array}{l}\text { Instalações físicas adequadas (confortáveis, arejadas, limpas, } \\
\text { iluminadas e silenciosas) }\end{array}$ & 5,65 & 3,74 & 1,91 \\
\hline $\begin{array}{l}\text { Equipamentos modernos que possam facilitar o processo de } \\
\text { atendimento }\end{array}$ & 5,75 & 3,64 & 2,11 \\
\hline Localização adequada dos Postos avançados de atendimento. & 5,65 & 4,11 & 1,54 \\
\hline Quantidade suficiente de colaboradores para atendimento & 5,75 & 3,88 & 1,87 \\
\hline Média total da dimensão & 5,70 & 3,84 & 1,85 \\
\hline
\end{tabular}

Fonte: Pesquisa de campo, 2009.

Observou-se que as percepções que os alunos-usuários possuem quanto às respostas da dimensão aspectos tangíveis não superam suas expectativas, pois todas as respostas apresentaram gaps ou hiatos positivos.

Tendo em vista a escala utilizada com opções que variavam de 1 a 7, o menor gap foi 1,54 , referente à localização adequada dos Postos Avançados de atendimento e o maior gap foi 2,11, referente a equipamentos modernos que possam facilitar o processo de atendimento.

Conforme os resultados apresentados na Tabela 4, a média total da dimensão da esfera serviço esperado apresentou o valor 5,70 e a média da esfera serviço percebido apresentou o valor 3,84. A média total dos gaps de Aspectos Tangíveis apresentou o valor 1,85. De uma forma geral, o serviço oferecido é considerado BOM, porém os gaps obtidos 
satisfazem a equação $\mathrm{E}>\mathrm{P}$, ou seja, as expectativas não foram superadas pelos serviços oferecidos. Porém, é possível inferir que apesar de não ter superado suas expectativas, os alunos-usuários estão satisfeitos quanto à localização dos Postos Avançados de atendimento.

\subsubsection{Confiabilidade}

Tabela 5 - Distribuição das respostas de acordo com a frequência.

\begin{tabular}{|c|c|c|c|c|c|c|c|}
\hline EXPECTATIVA & 1 & 2 & 3 & 4 & 5 & 6 & 7 \\
\hline Capacidade do atendente em esclarecer dúvidas & 2 & 2 & 8 & 14 & 20 & 40 & 114 \\
\hline Atualização das informações prestadas & 0 & 5 & 6 & 16 & 26 & 47 & 100 \\
\hline Cumprimento do serviço a que se propõe & 0 & 3 & 5 & 15 & 16 & 43 & 118 \\
\hline $\begin{array}{l}\text { Atendimento das solicitações dentro de um prazo } \\
\text { determinado }\end{array}$ & 1 & 0 & 6 & 13 & 26 & 55 & 99 \\
\hline
\end{tabular}

Fonte: Pesquisa de campo, 2009.

Tabela 6 - Distribuição das respostas de acordo com a frequência.

\begin{tabular}{|c|c|c|c|c|c|c|c|}
\hline PERCEPÇÃO & 1 & 2 & 3 & 4 & 5 & 6 & 7 \\
\hline Capacidade do atendente em esclarecer dúvidas & 9 & 22 & 46 & 45 & 45 & 25 & 8 \\
\hline Atualização das informações prestadas & 7 & 21 & 50 & 59 & 33 & 25 & 5 \\
\hline Cumprimento do serviço a que se propõe & 4 & 13 & 40 & 57 & 49 & 32 & 5 \\
\hline $\begin{array}{l}\text { Atendimento das solicitações dentro de um prazo } \\
\text { determinado }\end{array}$ & 14 & 18 & 40 & 55 & 38 & 26 & 9 \\
\hline
\end{tabular}

Fonte: Pesquisa de campo, 2009.

Tabela 7 - Médias obtidas na dimensão Confiabilidade

\begin{tabular}{|c|c|c|c|}
\hline Itens de medição da Confiabilidade & Expectativas & Percepções & Gaps \\
\hline Capacidade do atendente em esclarecer dúvidas & 6,12 & 4,01 & 2,11 \\
\hline Atualização das informações prestadas & 6,02 & 3,92 & 2,10 \\
\hline Cumprimento do serviço a que se propõe & 6,22 & 4,25 & 1,97 \\
\hline $\begin{array}{l}\text { Atendimento das solicitações dentro de um prazo } \\
\text { determinado }\end{array}$ & 6,12 & 3,99 & 2,13 \\
\hline Média total da dimensão & 6,12 & 4,04 & 2,07 \\
\hline
\end{tabular}

Fonte: Pesquisa de campo, 2009.

A confiabilidade reflete a consistência e a certeza do desempenho de uma organização. Considerada uma das dimensões mais importante para os teóricos da área de marketing, a confiabilidade é uma dimensão de alta relevância para a mensuração da qualidade dos serviços prestados aos usuários.

Conforme os resultado obtidos na Tabela 7, as expectativas obtiveram médias acima de 6 (muito importante), considerando uma escala de 1 a 7 , e as percepções apresentaram médias entre 3,92 e 4,04 (BOM).

O menor gap obtido, com média 1,97, refere-se ao item que avalia o cumprimento do serviço a que se propõe. O item que obteve o maior gap foi o que se refere ao "atendimento das solicitações dentro de um prazo determinado", com média 2,13. 
Diante dos gaps obtidos deduz-se que o usuário dos serviços espera muito mais do que aquilo que o setor de atendimento estudado está sendo capaz de lhe fornecer, isso significa uma descoberta preocupante na dimensão Confiabilidade.

De acordo com Cobra (2001, p.85) “com a falta de percepção de que o serviço da organização eventualmente pode não estar atendendo ao que o cliente espera, a organização pode estar prometendo algo que não está cumprindo".

\subsubsection{Presteza}

Tabela 8 - Distribuição das respostas de acordo com a frequência.

\begin{tabular}{l|c|c|c|c|c|c|c}
\hline EXPECTATIVA & $\mathbf{1}$ & $\mathbf{2}$ & $\mathbf{3}$ & $\mathbf{4}$ & $\mathbf{5}$ & $\mathbf{6}$ & $\mathbf{7}$ \\
\hline Horário de atendimento adequado & 2 & 3 & 6 & 24 & 39 & 59 & 67 \\
\hline $\begin{array}{l}\text { Tempo para atendimento } \\
\text { Acesso aos serviços oferecidos pela SAA (inclusive via }\end{array}$ & 2 & 4 & 8 & 28 & 39 & 67 & 52 \\
\hline $\begin{array}{l}\text { Divulgação de todas as informações e atualizações de } \\
\text { interesse do aluno-usuário }\end{array}$ & 0 & 3 & 8 & 23 & 25 & 68 & 73
\end{tabular}

Fonte: Pesquisa de campo, 2009.

Tabela 9 - Distribuição das respostas de acordo com a frequência.

\begin{tabular}{l|c|c|c|c|c|c|c}
\hline PERCEPÇÃO & $\mathbf{1}$ & $\mathbf{2}$ & $\mathbf{3}$ & $\mathbf{4}$ & $\mathbf{5}$ & $\mathbf{6}$ & $\mathbf{7}$ \\
\hline Horário de atendimento adequado & 26 & 30 & 35 & 44 & 38 & 19 & 8 \\
\hline $\begin{array}{l}\text { Tempo para atendimento } \\
\text { Acesso aos serviços oferecidos pela SAA (inclusive via }\end{array}$ & 25 & 33 & 51 & 43 & 26 & 16 & 6 \\
\hline $\begin{array}{l}\text { Divulgação de todas as informações e atualizações de } \\
\text { interesse do aluno-usuário }\end{array}$ & 24 & 29 & 54 & 43 & 31 & 16 & 3 \\
\hline
\end{tabular}

Fonte: Pesquisa de campo, 2009.

Tabela 10 - Médias obtidas na dimensão Presteza

\begin{tabular}{l|r|r|r}
\hline Itens de medição da Presteza & Expectativas & Percepções & Gaps \\
\hline Horário de atendimento adequado & 5,7 & 3,63 & 2,07 \\
\hline Tempo para atendimento & 5,53 & 3,86 & 1,67 \\
\hline $\begin{array}{l}\text { Acesso aos serviços oferecidos pela SAA (inclusive via } \\
\text { internet) }\end{array}$ & 5,70 & 3,42 & 2,28 \\
\hline $\begin{array}{l}\text { Divulgação de todas as informações e atualizações de } \\
\text { interesse do aluno-usuário }\end{array}$ & 5,83 & 3,44 & 2,39 \\
\hline Média total da dimensão & 5,69 & 3,58 & 2,10 \\
\hline
\end{tabular}

Fonte: Pesquisa de campo, 2009.

A dimensão da qualidade que avalia a presteza reflete o preparo de uma organização para prestar serviços, bem como horário de atendimento adequado e oportuno, tempo para atendimento, acesso aos serviços oferecidos e divulgações de informações. 
As percepções que os alunos-usuários possuem quanto às respostas da dimensão Presteza, não superam suas expectativas, pois todas as respostas apresentaram gaps ou hiatos positivos.

Tendo em vista a escala utilizada que varia de 1 a 7, o menor gap foi 1,67, referente ao tempo de atendimento e o maior foi de 2,39, referente à divulgação de informações.

Conforme os resultados apresentados na Tabela 10, a média total da dimensão da esfera serviço esperado apresentou o valor 5,69, e a média da esfera serviço percebido apresentou o valor 3,58. A média total dos gaps da dimensão Presteza apresentou o valor 2,10. Isto prova que, de uma forma geral, as expectativas não foram superadas pelos serviços oferecidos, pois o resultado obtido satisfaz a equação E $>$ P. Portanto, é possível inferir que os alunos-usuários de forma geral estão satisfeitos, no que se refere à Presteza, tendo em vista que as médias em todas as afirmativas ficaram próximas de 4 (BOM).

\subsubsection{Segurança}

Tabela 11 - Distribuição das respostas de acordo com a frequência.

\begin{tabular}{l|c|c|c|c|c|c|c}
\hline EXPECTATIVA & $\mathbf{1}$ & $\mathbf{2}$ & $\mathbf{3}$ & $\mathbf{4}$ & $\mathbf{5}$ & $\mathbf{6}$ & $\mathbf{7}$ \\
\hline Clareza na transmissão das informações & 0 & 2 & 4 & 19 & 33 & 56 & 86 \\
\hline Segurança transmitida pelo funcionário & 0 & 2 & 7 & 23 & 43 & 63 & 62 \\
\hline Organização dos funcionários no desempenho da função & 0 & 1 & 5 & 28 & 35 & 75 & 56 \\
\hline Esforço do funcionário para prestar um bom atendimento & 3 & 2 & 3 & 19 & 25 & 69 & 79 \\
\hline
\end{tabular}

Fonte: Pesquisa de campo, 2009.

Tabela 12 - Distribuição das respostas de acordo com a frequência.

\begin{tabular}{l|c|c|c|c|c|c|c}
\hline PERCEPÇÃO & $\mathbf{1}$ & $\mathbf{2}$ & $\mathbf{3}$ & $\mathbf{4}$ & $\mathbf{5}$ & $\mathbf{6}$ & $\mathbf{7}$ \\
\hline Clareza na transmissão das informações & 15 & 23 & 37 & 60 & 38 & 20 & 7 \\
\hline Segurança transmitida pelo funcionário & 9 & 21 & 49 & 60 & 36 & 19 & 6 \\
\hline Organização dos funcionários no desempenho da função & 8 & 19 & 46 & 64 & 35 & 24 & 4 \\
\hline Esforço do funcionário para prestar um bom atendimento & 23 & 23 & 41 & 46 & 30 & 25 & 12 \\
\hline
\end{tabular}

Fonte: Pesquisa de campo, 2009.

Tabela 13 - Médias obtidas na dimensão Segurança

\begin{tabular}{l|r|r|r}
\hline Itens de medição da Segurança & Expectativas & Percepções & Gaps \\
\hline Clareza na transmissão das informações & 5,97 & 3,86 & 2,11 \\
\hline Segurança transmitida pelo funcionário & 5,72 & 3,87 & 1,85 \\
\hline Organização dos funcionários no desempenho da função & 5,73 & 3,93 & 1,79 \\
\hline Esforço do funcionário para prestar um bom atendimento & 5,92 & 3,8 & 2,12 \\
\hline Média total da dimensão & 5,83 & 3,86 & 1,97 \\
\hline
\end{tabular}

Fonte: Pesquisa de campo, 2009. 
Entre as quatro questões utilizadas para mensurar esta dimensão, a que obteve menor gap foi a que se refere a "segurança transmitida pelo funcionário" no valor de 1,85, e o maior foi ao que se refere ao "esforço do funcionário para prestar um bom atendimento", no valor de 2,12 .

As expectativas obtiveram médias 5 (bem importante) e as percepções obtiveram médias entre 3,86 e 3,93, bem próxima de 4 (BOM).

Dentre as 4 afirmativas desta dimensão pode observar que nenhuma obteve gap negativo. Isso significa que as percepções que os alunos-usuários possuem quanto às respostas da dimensão Segurança não superam suas expectativas.

Tendo em vista a escala utilizada que varia de 1 a 7, o menor gap foi 1,79, referente à organização do funcionário no desempenho da função, e o maior foi 2,12, referente ao esforços do funcionário para prestar um bom atendimento.

Conforme os resultados apresentados na Tabela 13, a média total da dimensão da esfera serviço esperado apresentou o valor 5,83, e a média da esfera serviço percebido apresentou o valor 3,86. A média total dos gaps da dimensão Segurança apresentou o valor 1,97, o que demonstra que, de uma forma geral, o aluno-usuário está satisfeito, porém, as expectativas não foram superadas pelos serviços oferecidos, pois o resultado obtido equivale à equação $\mathrm{E}>\mathrm{P}$.

\subsubsection{Empatia}

Tabela 14 - Distribuição das respostas de acordo com a frequência.

\begin{tabular}{l|c|c|c|c|c|c|c}
\hline EXPECTATIVA & $\mathbf{1}$ & $\mathbf{2}$ & $\mathbf{3}$ & $\mathbf{4}$ & $\mathbf{5}$ & $\mathbf{6}$ & $\mathbf{7}$ \\
\hline $\begin{array}{l}\text { Entendimento do funcionário em relação à necessidade } \\
\text { do aluno-usuário. }\end{array}$ & 3 & 1 & 6 & 18 & 28 & 60 & 84 \\
\hline Atendimento individualizado & 4 & 5 & 13 & 28 & 50 & 54 & 46 \\
\hline Interesse em atender às solicitações & 3 & 3 & 3 & 24 & 39 & 61 & 67 \\
\hline Educação e gentileza dos funcionários & 4 & 0 & 2 & 22 & 26 & 42 & 104 \\
\hline
\end{tabular}

Fonte: Pesquisa de campo, 2009.

Tabela 15 - Distribuição das respostas de acordo com a frequência.

\begin{tabular}{l|c|c|c|c|c|c|c}
\hline PERCEPÇÃO & $\mathbf{1}$ & $\mathbf{2}$ & $\mathbf{3}$ & $\mathbf{4}$ & $\mathbf{5}$ & $\mathbf{6}$ & $\mathbf{7}$ \\
\hline $\begin{array}{l}\text { Entendimento do funcionário em relação à necessidade } \\
\text { do aluno-usuário. }\end{array}$ & 14 & 20 & 47 & 51 & 40 & 22 & 6 \\
\hline Atendimento individualizado & 13 & 26 & 36 & 63 & 32 & 22 & 8 \\
\hline Interesse em atender às solicitações & 30 & 23 & 45 & 50 & 29 & 16 & 7 \\
\hline Educação e gentileza dos funcionários & 29 & 22 & 38 & 53 & 21 & 28 & 9 \\
\hline
\end{tabular}

Fonte: Pesquisa de campo, 2009. 
Tabela 16 - Médias obtidas na dimensão Empatia

\begin{tabular}{|c|c|c|c|}
\hline Itens de medição da Empatia & Expectativas & Percepções & Gaps \\
\hline $\begin{array}{l}\text { Entendimento do funcionário em relação à necessidade do } \\
\text { aluno-usuário }\end{array}$ & 5,91 & 3,86 & 2,05 \\
\hline Atendimento individualizado & 5,30 & 3,86 & 1,44 \\
\hline Interesse em atender às solicitações & 5,72 & 3,50 & 2,21 \\
\hline Educação e gentileza dos funcionários & 6,04 & 3,67 & 2,36 \\
\hline Média total da dimensão & 5,74 & 3,72 & 2,01 \\
\hline
\end{tabular}

Fonte: Pesquisa de campo, 2009.

As quatro afirmativas referentes à dimensão Empatia representam também aspectos que precisam ser melhorados, pois apesar de apresentarem médias nos serviços percebidos próximas de 4 (BOM), apresentaram gaps positivos.. Entre as quatro questões utilizadas para mensurar esta dimensão, a que obteve menor gap foi a que se refere ao "atendimento individualizado" no valor de 1,44, e o maior gap foi ao que se refere a “educação e gentileza dos funcionários", no valor de 2,36. Isso significa uma descoberta preocupante na dimensão Empatia, pois o usuário dos serviços espera muito mais do que aquilo que o setor de atendimento estudado está sendo capaz de lhe fornecer.

Conforme os resultados apresentados na Tabela 16, a média total da dimensão da esfera serviço esperado apresentou o valor 5,74 e a média da esfera serviço percebido apresentou o valor 3,72. Portanto, é possível inferir que de forma geral o aluno-usuário está satisfeito.

\subsection{Verificação dos gaps por dimensão}

Tabela 17 - Gaps por dimensão

\begin{tabular}{l|r|r|r}
\hline \multirow{2}{*}{ DIMENSÃO } & \multicolumn{3}{c}{ MÉDIA } \\
\cline { 2 - 4 } Presteza & EXPECTATIVA & \multicolumn{1}{|c}{ PERCEPÇÃO } & \multicolumn{1}{c}{ GAPS } \\
\hline Confiabilidade & 5,69 & 3,58 & 2,10 \\
\hline Empatia & 6,12 & 4,04 & 2,07 \\
\hline Segurança & 5,74 & 3,72 & 2,01 \\
\hline Aspectos Tangíveis & 5,83 & 3,86 & 1,97 \\
\hline Média Total & 5,70 & 3,84 & 1,85 \\
\hline
\end{tabular}

Fonte: Pesquisa de campo, 2009.

Deve-se observar que, na Tabela 17, os gaps estão apresentados em ordem decrescente de classificação, onde, em todas as dimensões, a equação da qualidade que 
expressa os resultados foi $\mathrm{E}>\mathrm{P}$, obtendo na dimensão Aspectos Tangíveis e na dimensão Presteza, o menor e o maior gap respectivamente.

De acordo com os resultados observados na Tabela 17, a média das dimensões do módulo percepções apresentaram o valor 3,81. A média das dimensões do módulo de expectativas foi de 5,81, demonstrando que de maneira geral os alunos-usuários estão satisfeitos com os serviços oferecidos, porém esperam um melhor desempenho da SAA em todas as dimensões, pois de acordo com os gaps obtidos, os mesmos tem ficado muito aquém das expectativas geradas e por isso os gaps acabam sendo tão expressivos e preocupantes.

Não houve a ocorrência de atributos que satisfaçam a condição da equação da qualidade $\mathrm{E}=\mathrm{P}$ (Expectativa=Percepção) e nem que satisfaça a equação $\mathrm{E}<\mathrm{P}$. 


\section{CONCLUSÕES}

O objetivo desta pesquisa foi avaliar a qualidade dos serviços prestados pela Secretaria de Assuntos Acadêmicos (SAA) da Universidade de Brasília, com base nas expectativas e percepções dos alunos-usuários.

Com a aplicação da escala SERVQUAL, a pesquisa identificou lacunas em relação aos serviços oferecidos pela SAA, sendo mais expressivas em alguns itens das dimensões que mensuram a qualidade:

- Aspectos Tangíveis: equipamentos modernos que possam facilitar o processo de atendimento.

- Confiabilidade: atendimento das solicitações dentro de um prazo determinado.

- Presteza: divulgação de todas as informações e atualizações de interesse do aluno-usuário.

- Segurança: esforço do funcionário para prestar um bom atendimento.

- Empatia: educação e gentileza dos funcionários.

Pôde-se fazer uma análise "quantitativa", valorizando as dimensões sugeridas pelos autores da SERVQUAL.

Com base nos dados da pesquisa, percebeu-se um elevado grau de dissonância por parte dos alunos-usuários, entre o que esperam e o que percebem nos serviços prestados. Diante dos resultados obtidos recomenda-se uma investigação mais profunda, a fim de avaliar as causas da insatisfação dos alunos-usuários em todas as dimensões da escala.

A partir dos resultados dessa investigação presume-se a necessidade de melhorias na qualidade da oferta de serviços e na integração entre os atendentes e alunos-usuários.

Os serviços oferecidos podem alcançar a excelência por meio da persistência, expectativas superadas, conhecimento, empatia, segurança, qualidades, que devem ser almejadas por todos os colaboradores da organização.

Dentre os problemas enfrentados durante a pesquisa destaco o fato de não haver uma disciplina no Curso de Gestão Universitária, que aborde a área de Marketing, tão necessária para a realização de um estudo como este.

Para estudos futuros sugerem-se novas investigações sobre este tema que evidencie a qualidade no atendimento, como forma de contribuir para a cultura organizacional, aumento das competências individuais dos servidores e o aperfeiçoamento da gestão universitária. 


\section{REFERÊNCIAS}

ALBRECHT, K. A revolução nos serviços: como as empresas podem revolucionar a maneira de tratar seus clientes. São Paulo: Pioneira, 1998.

ASSOCIAÇÃO BRASILEIRA DE NORMAS TÉCNICAS. NBR ISO 9004-2: Gestão da qualidade e elementos do sistema da qualidade - Parte 2: Diretrizes para serviços. Rio de Janeiro, 1994.

AMARAL, P. A.; PINTO, W. G.; MIRANDA, A. L. Como gerenciar as expectativas na prestação de serviços. Cadernos discentes COPPEAD, Rio de Janeiro, n.11, p. 28-53, 2002.

BEBER, Sedinei José Nardelli. Estado atual dos estudos sobre a satisfação do consumidor. In: Anpad: http://anpad.org.br/enanpad/1999/dwn/enanpad1999-mkt-29.pdf

BRASIL, Ministério do Planejamento, Orçamento e Gestão, portal Gestão Pública. Disponível em: https://conteudo.gespublica.gov.br/menu_principal/gespublica/folder.200703-21.2806316778>. Acessado em 21 de abril de 2009.

BRASIL, Universidade de Brasília. Secretaria de Assuntos Acadêmicos (SAA). Disponível em <http://www.unb.br/administraçao/secretarias/saa Acesso em: 02/03/2009.

CARLZON, Jan. A Hora da Verdade. Rio de Janeiro: Sextante, 2005.

COBRA, M. Marketing de serviços. São Paulo: Cobra, 2001.

CORRÊA, H. L.; CAON, M. Gestão de serviços: lucratividade por meio de operações e de satisfação dos clientes. São Paulo: Atlas, 1992.

CUNHA, M. V. M; BORGES Jr. A. A.; FACHEL, J. M. G. Esquema CBF para mensuração da satisfação de clientes: um a proposta conceitual e prática. Anais Dio XXII. ENANPAD/Marketing, 1998.

CUNHA, N. R. S.. Avaliação da qualidade de serviços percebida utilizando a escala Servqual: o estudo de caso da PRODABEL. In Produção - Florianópolis, SC, Brasil, 03 a 05 de nov de 2004.

DANTAS, E. B. Atendimento ao público nas organizações: quando o marketing de serviço mostra a cara. SENAC. Brasília, 2004.

ELEUTÉRIO, S. A. V.; SOUZA, M. C. A. F. Qualidade na prestação de serviços: uma avaliação com clientes internos. Cadernos de Pesquisa em Administração. São Paulo. v. 09. $\mathrm{n}^{\circ} 03,2002$.

FERREIRA, M. C. Serviço de atendimento ao público: O que é? Como analisá-lo? Esboço de uma abordagem teórico-metodológica em ergonomia. Revista Multitemas, $n^{\circ}$ 16, p. 128-144, Editora UCDB, Campo Grande - MS, maio, 2000. 
FREITAS, A. L. P.; BOLSANELLO, F. M. C.; VIANA, N. R. N. G.. Avaliação da qualidade de serviços de uma biblioteca universitária: um estudo de caso utilizando o modelo Servqual. Revista Ciência da Informação. Brasília, v.37, n.3, 2008.

GIANESI, I. G. N; CORRÊA, H. L. Administração estratégica de serviços: operações para a satisfação do cliente. São Paulo: Atlas, 1994.

GRANUZZO, A; AUGUSTO, M. A; MATTOSINHO, P. Avaliação da qualidade de um serviço de algumas ferramentas úteis no gerenciamento da qualidade de serviços. Cadernos discentes COPPEAD, n. 4, p.30-57, 2000.

GRöNROOS, C. Marketing, gerenciamento e serviços - a competição por serviços na hora da verdade. Tradução Cristina Bazán. 5. ed. Rio de Janeiro: Campus, 1993.

Marketing: gerenciamento e serviços: a competição por serviços na hora da verdade. Rio de Janeiro: Campus, 1995.

HERCOS, B. V. S.; BEREZOVSKY, A. Qualidade do serviço oftalmológico prestado aos pacientes ambulatoriais do Sistema Único de Saúde - SUS. Arq. Bras. Oftalmologia. 2006.

HOSTENSKY, E. L. Atendimento ao público interno no Ministério da Educação: três olhares sobre o serviço de saúde prestado aos servidores. Dissertação (Mestrado em Psicologia) - Universidade de Brasília, Brasília, 2004.

KOOGAN, A. HOUAISS, A. Enciclopédia e dicionário ilustrado. Edições Delta. Rio de Janeiro, 1994.

KOTLER, P. Administração de marketing: análise, planejamento, implementação e controle. 5. ed. São Paulo: Atlas, 1998.

Administração de Marketing: análise, planejamento, implementação e controle. São Paulo; Atlas, 1996.

KOTLER, P.; ARMOSTRONG, G. Administração de Marketing. São Paulo: Atlas, 2001.

KOTLER, P.; KELLER, K. L. Administração de Marketing. 12. Edição - São Paulo: Pearson Pretence Hall, 2006.

LAS CASAS, A. L. marketing de Serviços. São Paulo: Atlas, 1991.

Qualidade total em serviços: conceitos, exercícios, casos práticos. São Paulo: Atlas, 1995.

LIMEIRA, T. M. V. E-Marketing: o marketing na internet com casos brasileiros. São Paulo: Saraiva, 2003.

LOVELOCK C.; WRIGHT, L. Serviços marketing e Gestão. Ed. Saraiva, 2003.

MARCELINO. G. F. (Org). Gestão Estratégica de universidade. Brasília: Universidade de Brasília, 2003. 
MARCHETTI, R. PRADO. P. H. M. Um Tour pelas medidas de satisfação do consumidor. Revista de Administração de Empresas. Vol. 41, n. 4. 2001.

MARSHALL JÚNIOR, I.; CIERCO, A. A.; ROCHA, A. V.; MOTA, E. B.; LEUSIN, S. Gestão da qualidade. $8^{\mathrm{a}}$ ed. Rio de Janeiro: FGV, 2006.

MATTAR, E. N. Pesquisa de marketing. São Paulo. Atlas, 1996.

MELLO, S. C. B; VIEIRA, R.S.G. FONSÊCA, F. R. B. F; NETO, A.F.S; GOUVEIA, T.B, CORDEIRO, A.T.B. Aplicação do modelo SERVQUAL para a avaliação da qualidade de serviço numa instituição de Ensino Superior baseado na percepção de alunos. In: XXII

Encontro Nacional de Engenharia de Produção. Curitiba - PR, 23 a 25 de outubro de 2002.

MELLO, S. C. B; DUTRA, H. F. O; OLIVEIRA, P. A. S. Avaliando a qualidade de serviço educacional numa IES: o impacto da qualidade percebida na apreciação do aluno de graduação. Revista Organização e Sociedade. Vol 08. n. 21. p 125-137. maio/ago, 2001.

MIGUEL, P. A. C.; SALOMI, G. E. Uma revisão dos modelos para medição da qualidade em serviços. Revista Produção. Vol 14 n.1. 2004.

OLIVEIRA, V. R. A. A prestação de um serviço público de qualidade: a divulgação eletrônica de informações do IBGE sob a óptica dos estudantes de Administração e Economia dos cursos de graduação da FGV/RJ em 2002. 2003, 119f. Dissertação (Mestrado em Administração Pública) - Fundação Getúlio Vargas, Rio de Janeiro, 2003.

PEREIRA, A. T.; FARIAS J. S. Avaliação da Qualidade dos Serviços prestados por um empreendimento hoteleiro: um caso estudado no litoral sergipano. In: XI Seminário de Pesquisa do CCSA/UFRN, 22 a 26/ago/2005.

RODRIGUES, A. C. M. Um a escala de mensuração da zona de tolerância de consumidores de serviço. Revista de Administração Contemporânea, v. 5, n.2, p.113-134, maio/ago, 2001.

SOARES, F. Serviços 5 estrelas: uma introdução a qualidade nos serviços. Rio de Janeiro: Qualitymark, 1994.

SPILK, A. Qualidade total e processo de subjetivação: um estudo junto aos servidores públicos federais. 2004. 116f. Dissertação (Mestrado em Psicologia Social e Institucional) Universidade Federal do Rio Grande do Sul, Rio Grande do Sul, 2004.

VERGARA, S. C. Começando a definir a metododologia. In: Projetos e relatórios de pesquisa em Administração. 3. ed. São Paulo: Atlas, 2000. Cap. 4, p.46-53. 
APÊNDICE 


\section{QUESTIONÁRIO}

Prezado (a) aluno (a):

O questionário a seguir serve de instrumento de coleta de dados para uma pesquisa de monografia, cujo tema é: QUALIDADE DO ATENDIMENTO EM UMA INSTITUIÇÃO FEDERAL DE ENSINO SUPERIOR.

Esta pesquisa apresenta duas fases: a primeira avaliará a sua expectativa em relação aos serviços oferecidos pela Secretaria de Assuntos Acadêmicos (SAA) da Universidade de Brasília, que sob seu ponto de vista, seja o ideal. A segunda fase avaliará sua percepção em relação aos serviços prestados pela SAA, além de tentar identificar o perfil do (a) aluno(a).

Por questões éticas, os dados coletados serão de caráter sigiloso, para isso, serão apresentados de forma agrupada, impossibilitando a identificação dos respondentes.

Agradeço previamente sua valiosa colaboração.

Alcione Sarah Santos Costa sarahcosta@unb.br 


\section{Fase 1: EXPECTATIVAS}

Baseando-se em sua experiência como aluno-usuário, idealize como seria uma SAA que prestaria uma excelente qualidade no atendimento. Em seguida mostre seu grau de concordância com as características que tal SAA possui em cada um dos enunciados. Se você acha que uma característica não é essencial para a excelente SAA, que você tem mente assinale o número 1. Caso contrário, se você acha que uma característica é imprescindível, assinale o número 7. Se suas impressões são menos fortes assinale um dos números intermediários que melhor represente o que você sente ou pensa, seguindo a classificação da escala de opinião a seguir:

\begin{tabular}{|c|c|c|c|c|c|c|}
\hline \multicolumn{7}{|c|}{ Classificação da Escala de Opinião (o que é importante) } \\
\hline Não é importante & $\begin{array}{c}\text { Pouco } \\
\text { importante }\end{array}$ & $\begin{array}{c}\text { Relativamente } \\
\text { importante }\end{array}$ & Importante & $\begin{array}{c}\text { Bem } \\
\text { importante }\end{array}$ & $\begin{array}{c}\text { Muito } \\
\text { importante }\end{array}$ & $\begin{array}{c}\text { Extremamente } \\
\text { importante } \\
\text { (imprescindível) } \\
\mathbf{1}\end{array}$ \\
$\mathbf{2}$ & $\mathbf{3}$ & $\mathbf{4}$ & $\mathbf{5}$ & $\mathbf{6}$ & $\mathbf{7}$ \\
\hline
\end{tabular}

\section{De acordo com sua EXPECTATIVA, emita sua opinião em relação aos aspectos abaixo, referentes a uma SAA.}

\section{Aspectos Tangíveis:}

\begin{tabular}{|c|c|c|c|c|c|c|c|c|}
\hline a) & Instalações físicas adequadas (confortáveis, arejadas, limpas, iluminadas e silenciosas). & 1 & 2 & 3 & 4 & 5 & & \\
\hline b) & Equipamentos modernos que possam facilitar o processo de atendimento & 1 & 2 & 3 & 4 & 5 & 6 & 7 \\
\hline c) & Localização adequada dos Postos avançados de atendimento & 1 & 2 & 3 & 4 & 5 & & \\
\hline d) & Quantidade suficiente de colaboradores para atendimento & 1 & 2 & 3 & 4 & 5 & & 7 \\
\hline
\end{tabular}

\section{Confiabilidade:}

\begin{tabular}{|c|c|c|c|c|c|c|c|c|}
\hline a) & Capacidade do atendente em esclarecer dúvidas & 1 & 2 & 3 & 4 & 5 & 6 & 7 \\
\hline b) & Atualização das informações prestadas & 1 & 2 & 3 & 4 & 5 & 6 & 7 \\
\hline c) & Cumprimento do serviço a que se propõe & 1 & 2 & 3 & 4 & 5 & 6 & 7 \\
\hline d) & Atendimento das solicitações dentro de um prazo determinado & $\mathbf{1}$ & 2 & 3 & 4 & 5 & 6 & 7 \\
\hline
\end{tabular}

\section{Presteza:}

Escala de opinião

\begin{tabular}{|c|c|c|c|c|c|c|c|c|}
\hline a) & Horário de atendimento adequado & 1 & 2 & 3 & 4 & 5 & & 7 \\
\hline b) & Tempo para atendimento & 1 & 2 & 3 & 4 & 5 & & 7 \\
\hline c) & Acesso aos serviços oferecidos pela SAA (inclusive via internet) & 1 & 2 & 3 & 4 & 5 & & 7 \\
\hline d) & Divulgação de todas as informações e atualizações de interesse do aluno-usuário & 1 & 2 & 3 & 4 & 5 & & 7 \\
\hline
\end{tabular}

\section{Segurança:}

\begin{tabular}{|l|l|l|}
\hline a) & Clareza na transmissão das informações & 1 \\
\hline b) & Segurança transmitida pelo funcionário & $\mathbf{1}$ \\
\hline c) & Organização dos funcionários no desempenho da função & 1 \\
\hline d) & Esforço do funcionário para prestar um bom atendimento & $\mathbf{1}$ \\
\hline
\end{tabular}

\section{Empatia}

\begin{tabular}{|l|l|r|r|r|r|r|r|r|}
\hline \multicolumn{2}{|l|}{ Empatia } & \multicolumn{5}{|c|}{ Escala de opinião } \\
\hline a) & Entendimento do funcionário em relação à necessidade do aluno-usuário. & $\mathbf{1}$ & $\mathbf{2}$ & $\mathbf{3}$ & $\mathbf{4}$ & $\mathbf{5}$ & $\mathbf{6}$ & $\mathbf{7}$ \\
\hline b) & Atendimento individualizado & $\mathbf{1}$ & $\mathbf{2}$ & $\mathbf{3}$ & $\mathbf{4}$ & $\mathbf{5}$ & $\mathbf{6}$ & $\mathbf{7}$ \\
\hline c) & Interesse em atender às solicitações & $\mathbf{1}$ & $\mathbf{2}$ & $\mathbf{3}$ & $\mathbf{4}$ & $\mathbf{5}$ & $\mathbf{6}$ & $\mathbf{7}$ \\
\hline d) & Educação e gentileza dos funcionários & $\mathbf{1}$ & $\mathbf{2}$ & $\mathbf{3}$ & $\mathbf{4}$ & $\mathbf{5}$ & $\mathbf{6}$ & $\mathbf{7}$ \\
\hline
\end{tabular}

Escala de opinião 


\section{Fase 2: PERCEPC̃̃̃O}

As afirmativas a seguir se relacionam com sua percepção e impressão em relação aos serviços recebidos pela SAA. Demonstre o seu grau de satisfação em relação às características que a SAA da Universidade de Brasília possui em cada um dos enunciados. Se você acha que o serviço recebido é péssimo, assinale o número 1. Caso contrário, se você acha que os serviços da SAA, são excelentes assinale o número 7. Se suas impressões são menos fortes assinale um dos números intermediários, seguindo a classificação da escala de opinião a seguir:

\begin{tabular}{|c|c|c|c|c|c|c|}
\hline \multicolumn{7}{|c|}{ Classificação da Escala de Opinião (o que é importante) } \\
\hline $\begin{array}{c}\text { Péssimo (não } \\
\text { atende às } \\
\text { expectativas) } \\
1\end{array}$ & Ruim & Regular & Bom & Muito Bom & Ótimo & $\begin{array}{c}\text { Excelente (atende } \\
\text { plenamente às } \\
\text { expectativas) } \\
7\end{array}$ \\
\hline
\end{tabular}

\section{De acordo com sua PERCEPÇÃO, emita sua opinião em relação aos aspectos abaixo, referentes a uma SAA.}

\section{Aspectos Tangíveis:}

\begin{tabular}{|c|c|c|c|c|c|c|c|c|}
\hline a & Instalações físicas adequadas (confortáveis, arejadas, limpas, iluminadas e silenciosas). & 1 & 2 & 3 & 4 & 5 & & \\
\hline b) & Equipamentos modernos que possam facilitar o processo de atendimento & 1 & 2 & 3 & 4 & 5 & 6 & 7 \\
\hline c) & Localização adequada dos Postos avançados de atendimento & 1 & 2 & 3 & 4 & 5 & & \\
\hline d) & Quantidade suficiente de colaboradores para atendimento & $\mathbf{1}$ & 2 & 3 & 4 & 5 & & 7 \\
\hline
\end{tabular}

\section{Confiabilidade:}

\begin{tabular}{|l|l|l|}
\hline a) & Capacidade do atendente em esclarecer dúvidas & \\
\hline b) & Atualização das informações prestadas & $\mathbf{1}$ \\
\hline c) & Cumprimento do serviço a que se propõe & \\
\hline d) & Atendimento das solicitações dentro de um prazo determinado & \\
\hline
\end{tabular}

\section{Presteza:}

Escala de opinião

a) Horário de atendimento adequado

b) Tempo para atendimento

c) Acesso aos serviços oferecidos pela SAA (inclusive via internet)

\begin{tabular}{l|l|l|l|l|l|l|}
$\mathbf{1}$ & $\mathbf{2}$ & $\mathbf{3}$ & $\mathbf{4}$ & $\mathbf{5}$ & $\mathbf{6}$ & $\mathbf{7}$ \\
\hline
\end{tabular}

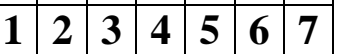

d) Divulgação de todas as informações e atualizações de interesse do aluno-usuário

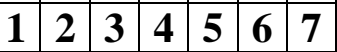

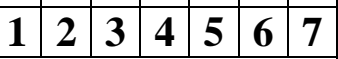

\section{Segurança:}

a) Clareza na transmissão das informações

b) Segurança transmitida pelo funcionário

Escala de opinião

c) Organização dos funcionários no desempenho da função

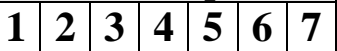

d) Esforço do funcionário para prestar um bom atendimento

\begin{tabular}{llllllll|}
$\mathbf{1}$ & $\mathbf{2}$ & $\mathbf{3}$ & $\mathbf{4}$ & $\mathbf{5}$ & $\mathbf{6}$ & $\mathbf{7}$ \\
\hline & $\mathbf{2}$ & $\mathbf{3}$ & $\mathbf{4}$ & $\mathbf{5}$ & $\mathbf{6}$ & $\mathbf{7}$
\end{tabular}

\begin{tabular}{llllllll|}
$\mathbf{1}$ & $\mathbf{2}$ & $\mathbf{3}$ & $\mathbf{4}$ & $\mathbf{5}$ & $\mathbf{6}$ & $\mathbf{7}$ \\
\hline
\end{tabular}

\begin{tabular}{llllllll|}
$\mathbf{1}$ & $\mathbf{2}$ & $\mathbf{3}$ & $\mathbf{4}$ & $\mathbf{5}$ & $\mathbf{6}$ & $\mathbf{7}$ \\
\hline
\end{tabular}

\section{Empatia}

\begin{tabular}{|c|c|c|c|c|c|c|c|}
\hline Lmi & patla & \multicolumn{6}{|c|}{ Escala de opmiao } \\
\hline a) & Entendimento do funcionário em relação à necessidade do aluno-usuário. & 12 & $2 \mid 3$ & 3 - 2 & 4 & 5 & \\
\hline b) & Atendimento individualizado & $\mathbf{1}$ & 2 & 3 & 4 ? & & 6 \\
\hline c) & Interesse em atender às solicitações & 1 & \begin{tabular}{l|l}
2 & 3 \\
\end{tabular} & 3 & 4 & & 6 \\
\hline d) & Educação e gentileza dos funcionários & 1 & \begin{tabular}{l|l}
2 & 3 \\
\end{tabular} & 3 - 3 & 4 & 5 & \\
\hline
\end{tabular}

Escala de opinião

d) Educação e gentileza dos funcionários 


\section{Fase 2: PERFIL DO ALUNO-USUÁRIO}

Por gentileza, responda as questões abaixo:
1. SEXO
(...) Masculino

(...) Feminino

\section{FAIXA ETÁRIA}

$$
\begin{aligned}
& \text { (...) } 18 \text { a } 20 \text { anos } \\
& \text { (...) } 21 \text { a } 30 \text { anos } \\
& \text { (...) } 31 \text { a } 40 \text { anos } \\
& \text { (...) acima de } 41 \text { anos }
\end{aligned}
$$

\section{ESTADO CIVIL}
(....) Solteiro (a)
(....) Casado (a)
(....) Divorciado (a)
(....) Viúvo (a)

\section{TEMPO QUE ESTÁ NA UNIVERSIDADE COMO ALUNO}
(....) 1 ano
(....) 2 anos
(....) 3 anos
(....) 4 anos
(....) 5 anos
(....) 6 anos
(....) 7 anos
(....) mais de 7 anos

\section{FOI OU É ALUNO DE OUTRA UNIVERSIDADE?}

$$
\text { (....) Sim }
$$

\section{VOCÊ TRABALHA?}

(....) Sim, sou funcionário com "vínculo empregatício" a uma organização/empresa

(....) Não sou funcionário e nem estagiário de nenhuma organização. Apenas estudante.

(....) Sou estagiário (a) de uma organização/empresa

\section{INDIQUE A RENDA MENSAL FAMILIAR}

(....) Abaixo de $\mathrm{R} \$ 500,00$

(....) Entre R $\$ 1.001,00-\mathrm{R} \$ 1.500,00$

(....) Entre R\$2.001,00 - R \$2.500,00

(....) Entre R $\$ 3.001,00-R \$ 3.500,00$

8. Indique seu curso:
(....) Entre R $\$ 501,00-\mathrm{R} \$ 1.000,00$

(....) Entre $\mathrm{R} \$ 1.501,00-\mathrm{R} \$ 2.000,00$

(....) Entre R \$2.501,00 - R \$3.000,00

(....) Acima de $\mathrm{R} \$ 3.500,00$ 